\title{
The role of frontal EEG asymmetry in post-traumatic stress disorder
}

Citation for published version (APA):

Meyer, T., Smeets, T., Giesbrecht, T., Quaedflieg, C. W. E. M., Smulders, F. T. Y., Meijer, E. H., \& Merckelbach, H. L. G. J. (2015). The role of frontal EEG asymmetry in post-traumatic stress disorder. Biological Psychology, 108, 62-77. https://doi.org/10.1016/j.biopsycho.2015.03.018

Document status and date:

Published: 01/05/2015

DOI:

10.1016/j.biopsycho.2015.03.018

Document Version:

Publisher's PDF, also known as Version of record

Document license:

Taverne

Please check the document version of this publication:

- A submitted manuscript is the version of the article upon submission and before peer-review. There can be important differences between the submitted version and the official published version of record.

People interested in the research are advised to contact the author for the final version of the publication, or visit the DOI to the publisher's website.

- The final author version and the galley proof are versions of the publication after peer review.

- The final published version features the final layout of the paper including the volume, issue and page numbers.

Link to publication

\footnotetext{
General rights rights.

- You may freely distribute the URL identifying the publication in the public portal. please follow below link for the End User Agreement:

www.umlib.nl/taverne-license

Take down policy

If you believe that this document breaches copyright please contact us at:

repository@maastrichtuniversity.nl

providing details and we will investigate your claim.
}

Copyright and moral rights for the publications made accessible in the public portal are retained by the authors and/or other copyright owners and it is a condition of accessing publications that users recognise and abide by the legal requirements associated with these

- Users may download and print one copy of any publication from the public portal for the purpose of private study or research.

- You may not further distribute the material or use it for any profit-making activity or commercial gain

If the publication is distributed under the terms of Article $25 \mathrm{fa}$ of the Dutch Copyright Act, indicated by the "Taverne" license above, 
Review article

\section{The role of frontal EEG asymmetry in post-traumatic stress disorder}

\section{Thomas Meyer*, Tom Smeets, Timo Giesbrecht, Conny W.E.M. Quaedflieg, Fren T.Y. Smulders, Ewout H. Meijer, Harald L.G.J. Merckelbach}

Faculty of Psychology and Neuroscience, Maastricht University, PO Box 616, 6200 MD Maastricht, The Netherlands

\section{A R T I C L E I N F O}

\section{Article history:}

Received 4 April 2014

Accepted 26 March 2015

Available online 3 April 2015

\section{Keywords:}

Frontal EEG asymmetry

Cerebral lateralization

Post-traumatic stress disorder

Depression

Anxiety

\begin{abstract}
A B S T R A C T
Frontal alpha asymmetry, a biomarker derived from electroencephalography (EEG) recordings, has often been associated with psychological adjustment, with more left-sided frontal activity predicting approach motivation and lower levels of depression and anxiety. This suggests high relevance to post-traumatic stress disorder (PTSD), a disorder comprising anxiety and dysphoria symptoms. We review this relationship and show that frontal asymmetry can be plausibly linked to neuropsychological abnormalities seen in PTSD. However, surprisingly few studies $(k=8)$ have directly addressed frontal asymmetry in PTSD, mostly reporting that trait frontal asymmetry has little (if any) predictive value. Meanwhile, preliminary evidence suggest that state-dependent asymmetry during trauma-relevant stimulation distinguishes PTSD patients from resilient individuals. Thus, exploring links between provocation-induced EEG asymmetry and PTSD appears particularly promising. Additionally, we recommend more fine-grained analyses into PTSD symptom clusters in relation to frontal asymmetry. Finally, we highlight hypotheses that may guide future research and help to fully apprehend the practical and theoretical relevance of this biological marker.
\end{abstract}

\section{Contents}

1. Introduction

2. Frontal EEG asymmetry and PTSD: What is the evidence?

2.1. Objectives

2.2. Methodological issues in frontal asymmetry research

2.2.1. Types of frontal asymmetry studies

2.2.2. Length and number of EEG recordings.

2.2.3. Reference scheme

2.3. Method

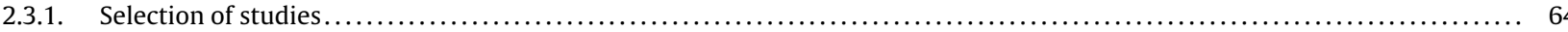

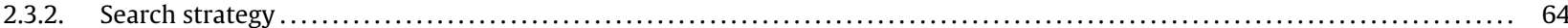

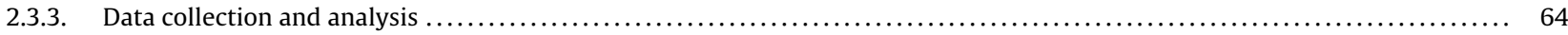

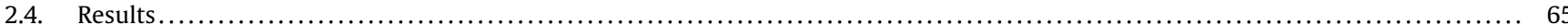

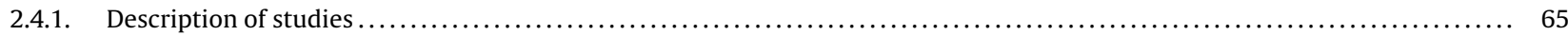

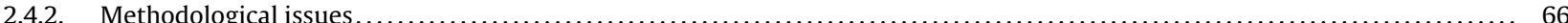

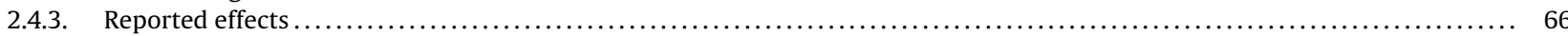

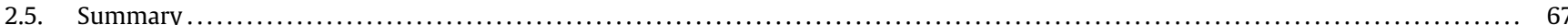

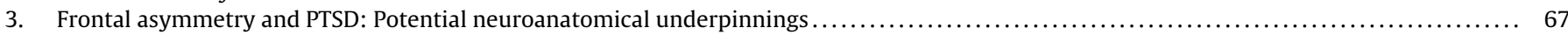

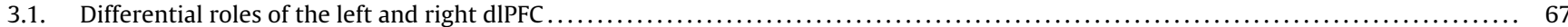

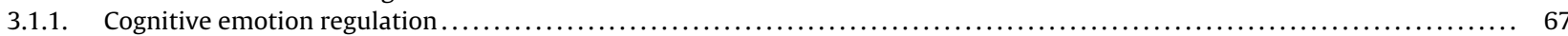

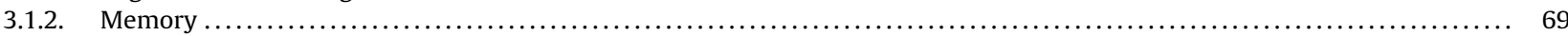

\footnotetext{
* Corresponding author. Tel.: +0031 43 3882486; fax: +0031433884196.

E-mail address: thomas.meyer@maastrichtuniversity.nl (T. Meyer).
} 
3.2. Left and right medial PFC and amygdala

3.2.1. Approach and withdrawal reactions.

.

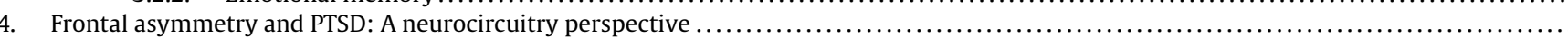

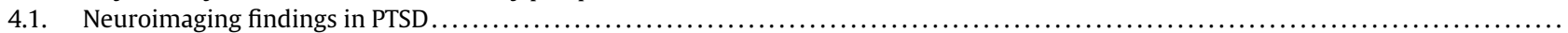

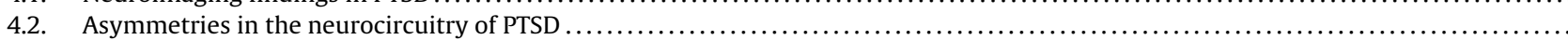

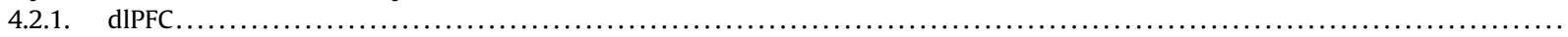

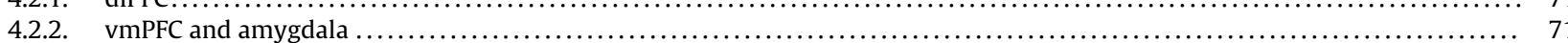

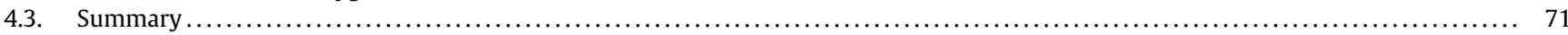

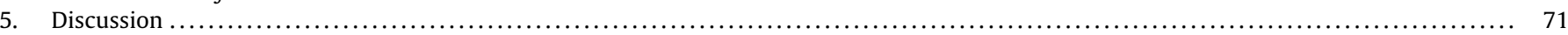

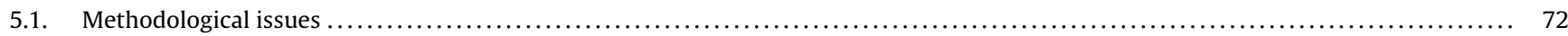

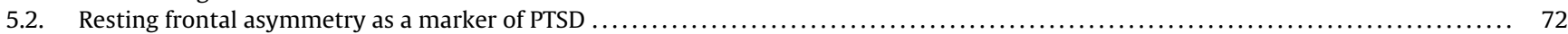

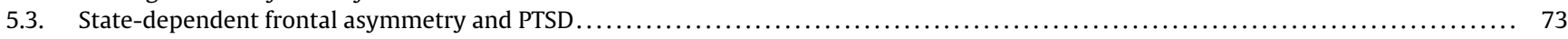

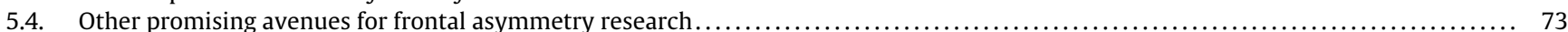

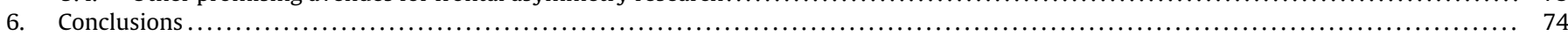

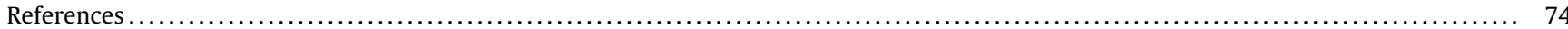

\section{Introduction}

At some point in their life, many people are exposed to potentially traumatic events, such as the death of a close friend, violent crimes, and severe accidents. Most people seem to be able to adapt well to aversive experiences (Bonanno, 2004, 2012; Bonanno \& Mancini, 2008), but a significant proportion develop post-traumatic stress disorder (PTSD). Victims with PTSD suffer from prolonged reactions to the traumatic event, including re-experiencing (e.g., intrusions, nightmares), avoidance of cues related to the trauma, altered mood and cognition, as well as exaggerated general arousal and reactivity (American Psychiatric Association, 2013). Strikingly, the severity of these symptoms is only modestly related to the objective severity of the traumatic event (Brewin, Andrews, \& Valentine, 2000; Kessler, Sonnega, Bromet, Hughes, \& Nelson, 1995; Kilpatrick, Resnick, \& Acierno, 2009; McNally \& Robinaugh, 2011). Therefore, researchers and clinicians alike have been intrigued by the question of what characterizes people who suffer from pathological symptoms after adversity, and whether there are biological markers to objectively measure these individual characteristics.

The search for objective indicators of PTSD is pressing for various reasons (Lehrner \& Yehuda, 2014; Zoellner, Bedard-Gilligan, Jun, Marks, \& Garcia, 2013). For instance, the diagnosis of this disorder essentially relies on self-report (Rosen \& Lilienfeld, 2008), and objective markers could be used for the development of more reliable diagnostic tests, with important implications for clinical and legal practice (Zoellner et al., 2013). Also, research into biological markers of PTSD helps to develop indicators of prognosis or treatment outcome and preventive interventions in high-risk groups (Lehrner \& Yehuda, 2014). This field of research has seen considerable progress in the recent years (for reviews, see: Schmidt, Kaltwasser, \& Wotjak, 2013; Zoladz \& Diamond, 2013). For instance, PTSD has been linked to increased stress hormone levels (Inslicht et al., 2011), stress hormone signaling (van Zuiden et al., 2012), physiological reactivity (Pole, 2007; Pole et al., 2009), or reduced extinction of conditioned fear (Lommen, Engelhard, Sijbrandij, van den Hout, \& Hermans, 2013).

The present article reviews literature on so-called frontal asymmetry as a potential objective indicator of PTSD symptoms following trauma exposure. Frontal asymmetry is a widely studied biomarker in research on emotional and behavioral reactions to stressful situations. It refers to a difference in mean alpha band power (typically $8-13 \mathrm{~Hz}$ ) between the left and right frontal cortex over a time span of several minutes, and is usually measured using electroencephalography (EEG; Coan \& Allen, 2003). A widespread interpretation of frontal asymmetry is based on the assumption that alpha band power is inversely related to brain activity, such that frontal asymmetry in alpha power reflects hemispheric differences in frontal brain activity (Pfurtscheller, Stancak, \& Neuper, 1996; though see Buzsaki \& Draguhn, 2004; Klimesch, Sauseng, \& Hanslmayr, 2007).

Theories of frontal asymmetry have linked this marker to the relative activity of two hypothesized brain systems in the left and right hemispheres, respectively, sub-serving positive affect or approach motivation, and negative affect or withdrawal motivation (Davidson, 1998; Heller, 1993). Accordingly, low levels of left-sided and high right-sided frontal activity are indicative of deficient approach motivation that might characterize depression, and exaggerated withdrawal tendencies that are typical for anxiety disorders. Based on this view, frontal asymmetry can also be expected to be associated with PTSD. That is, PTSD shares a number of fear-related symptoms with other anxiety disorders, whereas other symptoms are reminiscent of depression (Forbes et al., 2012). Yet another set of PTSD symptoms has been argued to reflect general distress symptoms, or levels of neuroticism, that are shared by a wide range of psychopathological conditions (Zoellner, Pruitt, Farach, \& Jun, 2014). Meanwhile, only re-experiencing symptoms, including dissociative amnesia and flashback memories, appear to be unique in PTSD (Brewin, 2011; Bryant, O'Donnell, Creamer, McFarlane, \& Silove, 2011).

Regarding depression and anxiety disorders, the available evidence indeed supports a link with frontal asymmetry, as has been shown in a meta-analysis including both types of patients (Thibodeau, Jorgensen, \& Kim, 2006). Thibodeau and colleagues revealed that that across studies, relatively more right-sided frontal activity at rest is linked to both depression and anxiety disorders. A smaller, similar association emerged for patients with comorbid depression and anxiety. Thus, there is good evidence that right-sided frontal activity is involved in current depression and anxiety disorders. This makes an association with PTSD conceivable. In addition, accumulating evidence points towards a specific link between frontal asymmetry and stress responding, with more right-sided activity predicting more extreme hormonal (Buss et al., 2003; Hewig et al., 2008; Lewis, Weekes, \& Wang, 2007; Quaedflieg, Meyer, Smulders, \& Smeets, 2015) and autonomic nervous system (Koslov, Mendes, Pajtas, \& Pizzagalli, 2011) responses. Despite these promising indications, a review of the empirical support for a link with PTSD is not yet available. Therefore, the first aim of the present article is to review the available evidence bearing on an involvement of frontal asymmetry in PTSD.

As noted above, studies addressing frontal asymmetry in relation to psychopathology typically link their findings to the relative activity of hypothesized brain systems in the left and right hemispheres for positive affect or approach motivation, and for negative affect or withdrawal motivation, respectively (Davidson, 1998; Heller, 1993). However, in line with what other authors have noted 
(e.g., Allen \& Kline, 2004; Davidson, 2004), we believe that a more in-depth analysis of the neuronal mechanisms underlying frontal asymmetry is essential for a full understanding of psychological adjustment to potentially traumatic experiences.

With these considerations in mind, we first provide a review of the frontal asymmetry literature on PTSD. Then, we explore how the potential neural origins of frontal asymmetry connect to our current neuropsychological understanding of PTSD, based on the available neuroimaging literature. Thereby, we aim to sketch a theoretical framework that links potential neural mechanisms underlying frontal asymmetry to neural and psychological abnormalities in PTSD. Finally, we discuss theoretical and practical implications of the findings and conclude by highlighting promising avenues for future research.

\section{Frontal EEG asymmetry and PTSD: What is the evidence?}

\subsection{Objectives}

We here provide the first systematic summary of empirical studies measuring frontal asymmetry as a potential correlate of PTSD, thereby adding to previous reviews on frontal asymmetry (e.g., Coan \& Allen, 2004; Harmon-Jones, Gable, \& Peterson, 2010) and more specifically, reviews on the relation between frontal asymmetry and mental disorders (e.g., Thibodeau et al., 2006). Our objective is to determine (1) whether PTSD is marked by relatively more right-sided frontal EEG activity when compared to groups of more resilient individuals, and (2) whether frontal asymmetry can be linked directly to the severity of PTSD symptoms. Given that methodological differences between studies may account for inconsistencies (Coan \& Allen, 2003; Hagemann, 2004; Reid, Duke, \& Allen, 1998), we first provide an overview of methodological aspects that deserve special attention.

\subsection{Methodological issues in frontal asymmetry research}

\subsubsection{Types of frontal asymmetry studies}

Studies investigating the relation between frontal EEG asymmetry and affective processes can be divided into two broad categories (Coan \& Allen, 2003). The first type of study measures frontal asymmetry while participants are in a resting state, and relates this asymmetry to various trait-like individual differences. The measure of interest in this type of study has been referred to as trait frontal asymmetry. In the second type of study, fluctuations in EEG asymmetry are investigated in relation to manipulations that intend to influence affective states (e.g., the Directed Facial Action Task; Coan, Allen, \& Harmon-Jones, 2001). The measure of interest in the latter type of study has been labeled state-dependent frontal asymmetry (e.g., Coan \& Allen, 2004). Notably, state-dependent frontal asymmetry during experimental emotion inductions has been argued to be reasonably stable and reflect meaningful individual differences in addition to trait frontal asymmetry (Coan, Allen, \& McKnight, 2006). In sum, trait frontal asymmetry and state-dependent frontal asymmetry during emotion processing may yield complementary information about individual differences in emotion, psychopathology, and possibly PTSD.

\subsubsection{Length and number of EEG recordings}

The length of EEG recording has been shown to be a crucial factor in the reliability of the frontal asymmetry measures. That is, the test-retest reliability of trait frontal asymmetry within a session has been shown to be good with $4 \mathrm{~min}$, and excellent with $8 \mathrm{~min}$ of measurement. State fluctuation can be reduced substantially by aggregating data from two or three measurement occasions (for a review, see Hagemann, 2004). In short, one would therefore expect that studies with longer recording periods yield more reliable findings.

\subsubsection{Reference scheme}

Studies of frontal asymmetry have employed different reference schemes for EEG measurement, with little evidence favoring any one of them as superior (Coan \& Allen, 2004; Hagemann, Naumann, \& Thayer, 2001). Typical reference schemes in frontal asymmetry studies are the common vertex reference $(\mathrm{Cz})$, computerized linked mastoids $(C L M)$ reference $(A 1+A 2)$, or average scalp reference. Differences between studies in the used reference schemes are often interpreted as mere source of noise (e.g., Coan et al., 2006), yet they may represent a serious threat to the comparability of studies. On a theoretical basis, the CLM is preferable among the most common reference schemes (for discussion of other reference techniques, including current source density, see, e.g., Hagemann, 2004; Jaworska et al., 2012; Tenke \& Kayser, 2005). For the purpose of this review, the inclusion of studies was not restricted to any particular reference scheme.

\subsection{Method}

\subsubsection{Selection of studies}

This review, to the best of our knowledge, includes all available peer-reviewed studies published in English that reported results of EEG asymmetry in humans, whereby either all participants or a defined subgroup were diagnosed with PTSD, in which case results were reported for each subgroup. The assessment of EEG asymmetry was required to be either a quantitative outcome variable (e.g., with diagnostic status or emotional states as independent variables) or a quantitative factor that was correlated to PTSD symptoms. We used no restriction as to whether resting state or task-related EEG asymmetry was measured. Neither was there a restriction concerning the design in which the measurement of EEG asymmetry was embedded (e.g., single assessment or treatment trials with follow-up measurements).

\subsubsection{Search strategy}

The Web of Science online search engine (ISI Web of Knowledge; Thompson Reuters, 2015) was used on to find relevant publications. Search terms were applied to Topic search and can be summarized in the formula asymmetr* AND (frontal OR anterior OR EEG OR alpha) AND (PTSD OR *trauma*). No other search restrictions were used. This approach yielded 260 hits in February 2015. Relevance of publications was evaluated by first assessing titles and abstracts provided by the search engine. Relevant studies were assessed in detail to determine whether selection criteria were met. As a second strategy, citing and cited references of selected publications were also assessed for relevance and included when the criteria were met.

\subsubsection{Data collection and analysis}

Publications were divided into studies that included frontal asymmetry as a trait-like variable (i.e., relying on resting state measures of frontal asymmetry) and those that included statedependent changes in frontal asymmetry. As another approach to categorize studies, we looked at the type of statistical technique used (e.g., correlational analyses between frontal asymmetry and PTSD symptoms vs. group comparisons, e.g., by means of ANOVA). We collected sample characteristics from all studies, including time elapsed since trauma, comorbidity, gender ratio, medication status, age, and methods used to diagnose PTSD or to quantify PTSD symptoms. Also, we recorded the following methodological aspects to evaluate the comparability of the studies: (1) length of EEG recording and number of measurement occasions; (2) the used reference 
Table 1

Summary of focus and sample characteristics of the included studies.

\begin{tabular}{|c|c|c|c|c|c|c|c|c|}
\hline Authors & Trait FA & State FA & Groups & $N$ & $\begin{array}{l}\text { Gender } \\
\text { ratio } \mathrm{M} / \mathrm{F}\end{array}$ & Age (SD) & Comorbidity & Medication \\
\hline \multirow[t]{3}{*}{ Metzger et al. (2004) } & Yes & No & PTSD & 16 & $0 / 18$ & NR; about 54 (4) & Current depression & None \\
\hline & & & past PTSD & 13 & $0 / 14$ & & & \\
\hline & & & Trauma non-PTSD & 13 & $0 / 18$ & & & \\
\hline \multirow[t]{4}{*}{ Rabe et al. (2006a) } & Yes & Yes & PTSD & $22^{\mathrm{b}}$ & $3 / 19$ & $42.5(11.64)$ & $\begin{array}{l}\text { Mood and anxiety } \\
\text { disorders }\end{array}$ & $\begin{array}{l}\text { None since }>1 \\
\text { month }\end{array}$ \\
\hline & & & Sub-PTSD & $21^{\mathrm{b}}$ & $7 / 14$ & $35.76(9.82)$ & & \\
\hline & & & Trauma non-PTSD & $21^{\mathrm{b}}$ & $10 / 11$ & $43.05(16.63)$ & & \\
\hline & & & Healthy controls & 23 & $7 / 16$ & $37.65(10.72)$ & & \\
\hline \multirow[t]{3}{*}{ Rabe et al. (2006b) } & Yes & No & PTSD & $23^{\mathrm{b}}$ & $4 / 19$ & $\begin{array}{l}\text { All subjects: } 41.54 \\
(13.19)\end{array}$ & $\begin{array}{l}\text { Mood and anxiety } \\
\text { disorders }\end{array}$ & $\begin{array}{l}\text { None since > } 1 \\
\text { month }\end{array}$ \\
\hline & & & Sub-PTSD & $22^{\mathrm{b}}$ & $6 / 16$ & & & \\
\hline & & & Trauma non-PTSD & $37^{\mathrm{b}}$ & $17 / 20$ & & & \\
\hline \multirow[t]{2}{*}{ Rabe et al. (2008) } & Yes & Yes & $\begin{array}{l}\text { PTSD and sub-PTSD } \\
\text { treatment }\end{array}$ & $17^{\mathrm{b}}$ & $2 / 15$ & $38.65(11.47)$ & $\begin{array}{l}\text { Mood and anxiety } \\
\text { disorders }\end{array}$ & $\begin{array}{l}\text { None since }>1 \\
\text { month }\end{array}$ \\
\hline & & & $\begin{array}{l}\text { PTSD and sub-PTSD } \\
\text { waitlist }\end{array}$ & $18^{\mathrm{b}}$ & $8 / 10$ & $41.89(11.03)$ & & \\
\hline \multirow[t]{2}{*}{ Shankman et al. (2008) } & Yes & No & PTSD & $32^{c}$ & $16 / 16$ & $40.7(11.3)$ & NR & $\begin{array}{l}\text { NR; present in } \\
\text { "many" cases (p. } \\
196)\end{array}$ \\
\hline & & & Healthy controls ${ }^{\mathrm{a}}$ & $42^{c}$ & $27 / 15$ & $36.0(14.0)$ & & \\
\hline \multirow[t]{3}{*}{ Kemp et al. (2010) } & Yes & No & PTSD & $14^{\mathrm{b}}$ & $5 / 9$ & $41.4(12.3)$ & NR & $\begin{array}{l}5 \text { PTSD patients } \\
\text { medicated } \\
\text { antidepressants }\end{array}$ \\
\hline & & & Depression & 15 & $6 / 9$ & $39.9(14.0)$ & & \\
\hline & & & Healthy controls & $15^{\mathrm{d}}$ & $6 / 9$ & $42.4(16.7)$ & & \\
\hline \multirow[t]{2}{*}{ Gordon et al. (2010) } & Yes & No & PTSD & $48^{c}$ & $25 / 23$ & $\mathrm{NR}$ & NR & NR \\
\hline & & & Healthy controls & $1908^{c}$ & $971 / 937$ & NR; range: 6-87 & & \\
\hline \multirow[t]{2}{*}{ Wahbeh and Oken (2013) } & Yes & No & PTSD & $59^{e}$ & $59 / 0$ & $54.4(11.5)$ & NR & $\begin{array}{l}\text { Stable for }>1 \\
\text { month }\end{array}$ \\
\hline & & & Trauma non-PTSD & $27^{e}$ & $27 / 0$ & $53.1(11.3)$ & & \\
\hline
\end{tabular}

Note. $\mathrm{FA}=$ frontal asymmetry; $\mathrm{M} / \mathrm{F}=$ male/female; $\mathrm{NR}=$ not reported; Sub-PTSD = patients with sub-clinical PTSD symptoms.

a Control participants were required to score low on neuroticism and high on extraversion, and to show no stress or anxiety symptoms.

b Substantial overlap ( $>30 \%$ ) of the sample with another study.

c Sample potentially overlaps with that of another study, but the proportion could not be determined.

d Partial overlap $(<30 \%)$ of the sample with another study.

e Seven participants from the combined sample were excluded from the analyses.

scheme; (3) the electrode sites used to assess frontal asymmetry; and (4) reported procedural details that may be relevant for wanted or unwanted variation in motivational states during the EEG measurements.

\subsection{Results}

\subsubsection{Description of studies}

The online search yielded 10 publications that were considered directly relevant to this review. Eight publications fulfilled the inclusion criteria, whereas one study was excluded because PTSD symptoms were not formally assessed (Curtis \& Cicchetti, 2007) and one study was excluded as it was published in Russian (Kurchakova, Tarabrina, Illarionova, \& Grishkova, 2009). Among the cited references in the included publications, one additional study was relevant but did not fulfill the inclusion criteria (McCaffrey, Lorig, Pendrey, McCutcheon, \& Garrett, 1993; frontal asymmetry derived by period analysis rather than spectral analysis). Among the eight included publications, three stem from the same research group (Rabe, Beauducel, Zöllner, Maercker, \& Karl, 2006a; Rabe, Zöllner, Beauducel, Maercker, \& Karl, 2008; Rabe, Zöllner, Maercker, \& Karl, 2006b). Three other publications used participant data retrieved from the Brain Resource International Database (BRID; http://brainnet.org.au). While it was not possible to calculate the exact number of unique participants, our most conservative estimate is that this review pertains to a total of 139 patients diagnosed with PTSD. Additionally, single-occasion frontal asymmetry data were used from healthy or matched control participants $(n=79)$, participants that were exposed to a traumatic situation, but did not develop PTSD $(n=70)$, patients with sub-clinical
PTSD symptoms $(n=22)$, and from participants with lifetime but no current diagnosis of PTSD $(n=13)$. One study (Rabe et al., 2008) assessed changes in frontal asymmetry on two occasions in two groups of PTSD patients, one receiving therapy between occasions and the other serving as a waiting list control group. One study (Gordon, Palmer, \& Cooper, 2010) compared frontal asymmetry in a PTSD group with normative data from a large control sample. Table 1 presents an overview of the included studies.

With respect to analyses of trait frontal asymmetry, six publications (Gordon et al., 2010; Kemp et al., 2010; Rabe et al., 2006a, 2008; Shankman et al., 2008; Wahbeh \& Oken, 2013) report analyses of group differences in frontal asymmetry at rest, and six publications (Kemp et al., 2010; Metzger et al., 2004; Rabe et al., 2006a, 2006b; Shankman et al., 2008; Wahbeh \& Oken, 2013) report correlation analyses regarding resting frontal asymmetry and PTSD symptom severity. Gordon et al. (2010) compared frontal asymmetry scores of 48 PTSD patients with normative scores derived from 1908 healthy controls. The average cell sizes in the other group analyses ranged from $n=14.7$ to $n=43.0(M=25.0, \mathrm{SD}=11.3)$. Sample sizes in the correlation analyses ranged from $N=14$ to $N=82$ $(M=49.7, \mathrm{SD}=25.7)$.

Two publications (Rabe et al., 2006a, 2008) also focused on state-dependent frontal asymmetry, reporting analyses of group differences in state-dependent frontal asymmetry as well as correlational analyses. Rabe and colleagues addressed state-dependent frontal asymmetry using tasks that aimed to activate trauma memories and inductions of trauma-unrelated fear and positive emotions, using images from the International Affective Picture System (IAPS; Lang, Bradley, \& Cuthbert, 2005). 
Table 2

Methodological details of the included studies.

\begin{tabular}{|c|c|c|c|c|c|c|}
\hline Authors & Reference & Frontal sites & State/trait & Occasions & $\begin{array}{l}\text { Recording } \\
\text { length }(s)\end{array}$ & Procedural details \\
\hline Metzger et al. (2004) & CLM & $\mathrm{F} 3 / \mathrm{F} 4$ & Trait & 1 & 360 & $3 \mathrm{~min} \mathrm{EO}, 3 \mathrm{~min} \mathrm{EC}$ \\
\hline \multirow[t]{2}{*}{ Rabe et al. (2006a) } & \multirow[t]{2}{*}{ CLM } & \multirow[t]{2}{*}{ Avg F3, F7, T7/Avg F4, F8, T8 } & State & 1 & 60 & $\begin{array}{l}60 \text { s periods for each mood induction, } \\
120 \text { s pause between inductions }\end{array}$ \\
\hline & & & Trait & 1 & 480 & $4 \min \mathrm{EO}, 4 \mathrm{~min} \mathrm{EC}$ \\
\hline Rabe et al. (2006b) & CLM & $\mathrm{FC} 1 / \mathrm{FC} 2$ & Trait & 1 & 480 & $4 \mathrm{~min} \mathrm{EO}, 4 \mathrm{~min} \mathrm{EC}$ \\
\hline \multirow[t]{2}{*}{ Rabe et al. (2008) } & \multirow[t]{2}{*}{ CLM } & \multirow[t]{2}{*}{ Avg F3, F7, T7/Avg F4, F8, T8 } & State & 2 (change) & 60 & $\begin{array}{l}60 \text { s periods for each mood induction, } \\
120 \text { s pause between inductions }\end{array}$ \\
\hline & & & Trait & 2 (change) & 480 & $4 \min \mathrm{EO}, 4 \mathrm{~min} \mathrm{EC}$ \\
\hline Shankman et al. (2008) & $\begin{array}{l}\text { Scalp average } \\
\text { ( } 24 \text { electrodes) }\end{array}$ & $\mathrm{F} 3 / \mathrm{F} 4$ & Trait & 1 & 240 & $2 \min \mathrm{EO}, 2 \mathrm{~min} \mathrm{EC}$ \\
\hline Kemp et al. (2010) & CLM & F3/F4 & Trait & 1 & 120 & $2 \min \mathrm{EC}$ \\
\hline Gordon et al. (2010) & CLM & $\mathrm{FC} 3 / \mathrm{FC} 4$ & Trait & 1 & 240 & $2 \min \mathrm{EO}, 2 \mathrm{~min} \mathrm{EC}$ \\
\hline Wahbeh and Oken (2013) & Local average & $\mathrm{F} 3 / \mathrm{F} 4$ & Trait & 1 & $\sim 240$ & $\begin{array}{l}5 \text { min EC while participants } \\
\text { discriminated simple tones occurring } \\
\text { every } 4-14 \mathrm{~s}\end{array}$ \\
\hline
\end{tabular}

Note. $\mathrm{EO}=$ eyes open; $\mathrm{EC}=$ eyes closed.

\subsubsection{Methodological issues}

The characteristics of the included samples are summarized in Table 1. In all studies, the Clinician Administered PTSD Scale (CAPS; Blake et al., 1995) was used as the basis for group allocation (e.g., PTSD, resilient) and/or to quantify PTSD symptom severity. Type of trauma was war experiences in two studies (Metzger et al., 2004; Wahbeh \& Oken, 2013), motor vehicle accidents in the three Rabe et al. studies, and various or non-specified trauma types in the three remaining studies (Gordon et al., 2010; Kemp et al., 2010; Shankman et al., 2008). Also notably, while the latter three studies do not report on comorbidity, comorbid mood and anxiety disorders were present in the other studies. Current psychoactive medication was present in three studies (Kemp et al., 2010; Shankman et al., 2008; Wahbeh \& Oken, 2013), not reported in one (Gordon et al., 2010), and absent in the other studies.

Table 2 summarizes methodological details regarding the EEG recordings in each study. As can be seen, most studies used the CLM reference scheme, whereas two used an average reference scheme (Shankman et al., 2008; Wahbeh \& Oken, 2013). Most studies focused on lateral frontal electrodes for the measurement of frontal asymmetry, including the paired electrode sites F3/F4, FC1/FC2, or FC3/FC4, whereas two studies from the Rabe group (Rabe et al., 2006a, 2008) also included more lateral and more posterior electrodes for the calculation of frontal asymmetry, by averaging the power density values of F3, F7, and
T7 as well as F4, F8, and T8. Recording length in trait frontal asymmetry studies ranged from 120 to $480 \mathrm{~s}$ across studies. Measurements were restricted to one occasion in all studies, although Rabe et al. (2008) used measurements from two occasions to derive frontal asymmetry change scores. All assessments of state frontal asymmetry were based on $60 \mathrm{~s}$ measurements during mood inductions.

\subsubsection{Reported effects}

The reported results concerning trait frontal asymmetry are summarized in Table 3. As can be seen, all studies failed to find significant group differences in trait frontal asymmetry. Likewise, all but one study found small and non-significant correlations between trait frontal asymmetry and CAPS scores in PTSD patients or across trauma groups. By contrast, the Kemp et al. (2010) study reports a relatively large negative correlation $(r=-.62)$ between frontal asymmetry and CAPS scores, indicating that more left-sided frontal activity was associated with fewer PTSD symptoms. Because of overlapping participant samples in the studies, we were not able to calculate a valid average correlation between frontal asymmetry and CAPS scores.

Table 4 summarizes the results concerning state-dependent frontal asymmetry. As can be seen, PTSD patients displayed significantly stronger right-sided activation in response to traumarelated stimuli in the Rabe et al. (2006a) study. Moreover, the

Table 3

Trait frontal asymmetry: correlations and group analyses.

\begin{tabular}{|c|c|c|c|c|c|c|c|}
\hline Authors & $\begin{array}{l}\text { Group } \\
\text { comparison }\end{array}$ & Statistic $(d f)$ & $p$ & $\begin{array}{l}\text { Correlation } \\
\text { analysis }\end{array}$ & $r(N)$ & $p$ & Findings \\
\hline Metzger et al. (2004) & No & - & - & Yes & $-.09(42)$ & $n s$. & No correlation with CAPS scores across groups \\
\hline Rabe et al. (2006a) & Yes & $F \mathrm{NR}(3,79)$ & $n s$. & Yes & $.07(64)$ & $n s$. & $\begin{array}{l}\text { No differences between groups; no correlation } \\
\text { with CAPS scores across groups }\end{array}$ \\
\hline Rabe et al. (2006b) & No & - & - & Yes & $-.06(82)$ & ns. & No correlation with CAPS scores across groups \\
\hline Rabe et al. (2008) & Yes & $F$ NR $(1,33)$ & $n s$. & No & - & - & $\begin{array}{l}\text { No group differences in FA change (therapy vs. } \\
\text { waitlist) }\end{array}$ \\
\hline Shankman et al. (2008) & Yes & $F<1(1,72)$ & ns. & Yes & n.r. (32) & $n s$. & $\begin{array}{l}\text { No difference between patients and controls; } \\
\text { no correlation with CAPS scores in the PTSD } \\
\text { group }\end{array}$ \\
\hline Kemp et al. (2010) & Yes & $t \mathrm{NR}(27)$ & $n s$. & Yes & $-.62(14)$ & .02 & $\begin{array}{l}\text { No differences between groups; left-sided } \\
\text { frontal activity correlated negatively with } \\
\text { CAPS scores in patients }\end{array}$ \\
\hline Gordon et al. (2010) & Yes & $t \mathrm{NR}(47)$ & $n s$. & No & - & - & $\begin{array}{l}\text { Patients within normal range of FA, } \\
\text { non-significant propensity towards more } \\
\text { right-sided activity }\end{array}$ \\
\hline Wahbeh and Oken (2013) & Yes & $F<1(1,77)$ & .44 & Yes & n.r. (79) & $n s$. & $\begin{array}{l}\text { No differences between groups; no correlation } \\
\text { with CAPS scores across groups }\end{array}$ \\
\hline
\end{tabular}

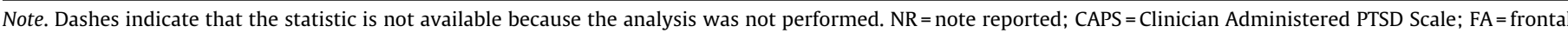
asymmetry. 
Table 4

State-dependent frontal asymmetry: correlations and group analyses.

\begin{tabular}{|c|c|c|c|c|c|c|c|c|}
\hline Authors & Induction $^{\mathrm{a}}$ & ANOVA & $F(\mathrm{df})$ & $p$ & Correlation analysis & $r(N)$ & $p$ & Findings \\
\hline \multirow[t]{3}{*}{$\begin{array}{l}\text { Rabe et al. } \\
\text { (2006a) }\end{array}$} & Trauma & FA between groups & $3.97(3,79)$ & $<.05$ & FA with CAPS & $-.44(64)$ & $<.01$ & $\begin{array}{l}\text { Significant group difference in } \\
\text { activation FA, with PTSD and sub-PTSD } \\
\text { group displaying a trend of stronger } \\
\text { right-sided activation, and trauma } \\
\text { non-PTSD displaying more left-sided } \\
\text { activation; More right-sided activation } \\
\text { associated with higher CAPS scores } \\
\text { across trauma groups }\end{array}$ \\
\hline & Fear & FA between groups & NR $(3,79)$ & $n s$. & FA with CAPS & $-.05(64)$ & $n s$. & $\begin{array}{l}\text { No group differences in activation FA; } \\
\text { no association with CAPS scores }\end{array}$ \\
\hline & Positive & FA between groups & NR $(3,79)$ & $n s$. & FA with CAPS & $-.09(64)$ & $n s$. & $\begin{array}{l}\text { No group differences in activation FA; } \\
\text { no association with CAPS scores }\end{array}$ \\
\hline \multirow[t]{5}{*}{$\begin{array}{l}\text { Rabe et al. } \\
\text { (2008) }\end{array}$} & Trauma & $\begin{array}{l}\text { FA change between } \\
\text { groups }\end{array}$ & $3.49(1,33)$ & .07 & $\begin{array}{l}\text { FA change with CAPS } \\
\text { change }\end{array}$ & $.08(35)$ & .44 & $\begin{array}{l}\text { Trend-significant effect of treatment } \\
\text { vs. waitlist on FA change, but } \\
\text { significant FA change within treatment } \\
\text { group; change in FA unrelated to CAPS } \\
\text { change, but decrease in right-sided } \\
\text { activation associated with reduction of } \\
\text { CAPS scores. }\end{array}$ \\
\hline & & $\begin{array}{l}\text { FA change in } \\
\text { treated group }\end{array}$ & $7.9(1,16)$ & .01 & $\begin{array}{l}\text { R-change with CAPS } \\
\text { change }\end{array}$ & $.39(35)$ & .02 & \\
\hline & & & & & $\begin{array}{l}\text { L-change with CAPS } \\
\text { change }\end{array}$ & $.26(35)$ & .13 & \\
\hline & Fear & $\begin{array}{l}\text { FA change between } \\
\text { groups }\end{array}$ & NR $(1,33)$ & $n s$. & No & - & - & $\begin{array}{l}\text { No effect of treatment vs. waitlist on } \\
\text { FA change }\end{array}$ \\
\hline & Positive & $\begin{array}{l}\text { FA change between } \\
\text { groups }\end{array}$ & NR $(1,33)$ & $n s$. & No & - & - & $\begin{array}{l}\text { No effect of treatment vs. waitlist on } \\
\text { FA change }\end{array}$ \\
\hline
\end{tabular}

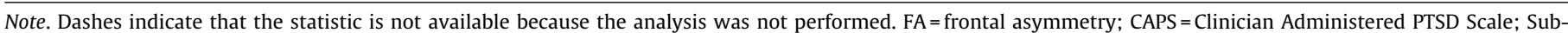
PTSD = patients with sub-clinical PTSD symptoms; R-change = change in right frontal activation; L-change = change in left frontal activation; NR = not reported.

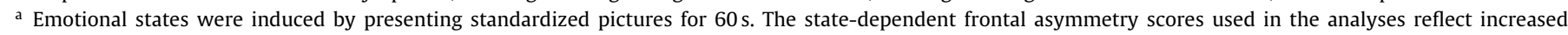
right-sided activation (decreased right-sided alpha power) relative to a control condition in which a neutral picture was shown.

latter study found a significant positive correlation between relatively more right-sided activation in this condition and CAPS scores. Additionally, Rabe et al. (2008) found that relatively rightsided activation in response to trauma-related stimuli decreased significantly in patients who received cognitive-behavioral treatment (CBT), but this decrease was only marginally stronger than that in the waitlist control group. Moreover, changes in frontal asymmetry across both groups were unrelated to improvement in PTSD symptoms. However, the decrease in right-sided activation (irrespective of left-sided activation) was significantly associated with a reduction in PTSD symptoms. With respect to the induction of positive emotion and trauma-unrelated fear, the two studies found no group differences in activation asymmetry, no correlation of activation asymmetry with PTSD symptoms, and no changes in activation asymmetry attributable to CBT.

\subsection{Summary}

We reviewed empirical studies that directly assessed whether PTSD is marked by abnormal frontal EEG asymmetry. All eight studies that fulfilled our criteria included trait frontal asymmetry, while two additionally focused on state-dependent frontal asymmetry, in relation to PTSD symptoms. Surprisingly, only one study found a relationship between trait frontal asymmetry and PTSD symptoms, with increased right-sided frontal activity predicting more severe symptoms. The two publications focusing on statedependent frontal asymmetry (Rabe et al., 2006a, 2008) found that higher right-sided frontal activation in response to trauma-related stimuli, but not unrelated negative stimuli, correlates with PTSD symptoms. Together, these data suggest that state frontal asymmetry during exposure to trauma-relevant stimuli may distinguish PTSD patients from resilient and from trauma-free individuals, while the evidence regarding trait frontal asymmetry still remains inconclusive.

\section{Frontal asymmetry and PTSD: Potential neuroanatomical underpinnings}

Following the review of EEG studies with PTSD patients, we now aim to sketch a theoretical framework that links frontal asymmetry to neural and psychological abnormalities in PTSD. For this purpose, we first explore potential neuroanatomical underpinnings of frontal asymmetry and psychological functions associated with these brain areas-with a particular focus on motivational responses, emotion regulation, and memory. In line with the finding that EEG alpha activity corresponds with lowered blood oxygen level-dependent (BOLD) signals in the cortical areas underneath the electrodes (Goldman, Stern, Engel, \& Cohen, 2002; Laufs et al., 2003), we follow the assumption frontal asymmetry results from asymmetric activity in the dorsolateral prefrontal cortex (dlPFC; see Fig. 1, panel a; Pizzagalli, Sherwood, Henriques, \& Davidson, 2005). In addition, we follow the proposition that frontal asymmetry results from functional lateralization in widespread neuronal systems, prominently featuring the ventromedial PFC (vmPFC) and the amygdala (Davidson, 1998). Then, in the next section, we outline the current neuropsychological understanding of PTSD and focus specifically on potential asymmetric activity in this disorder, based on the available neuroimaging literature.

\subsection{Differential roles of the left and right dIPFC}

\subsubsection{Cognitive emotion regulation}

Functional magnetic resonance imaging (fMRI) studies suggest that the dIPFC mediates cognitive aspects of emotion regulation. For instance, the lateral PFC is implicated in cognitive reappraisal (Drabant, McRae, Manuck, Hariri, \& Gross, 2009; Ochsner \& Gross, 2005; but see Kompus, Hugdahl, Öhman, Marklund, \& Nyberg, 2009), an emotion regulation strategy that aims to alter emotional valence by changing interpretations of a situation (Gross \& Thompson, 2007). Also, cognitive modification of implicit 
a)

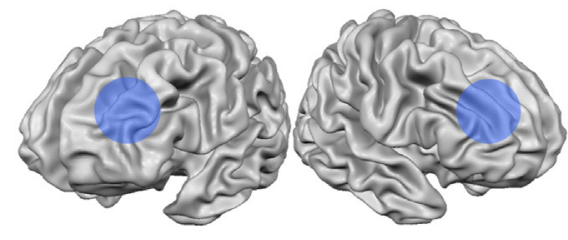

dIPFC

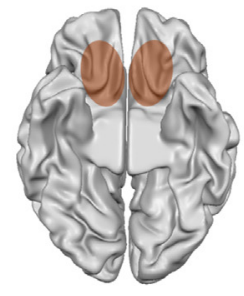

vmPFC

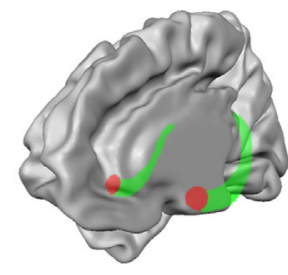

Hippocampus (green)

b)

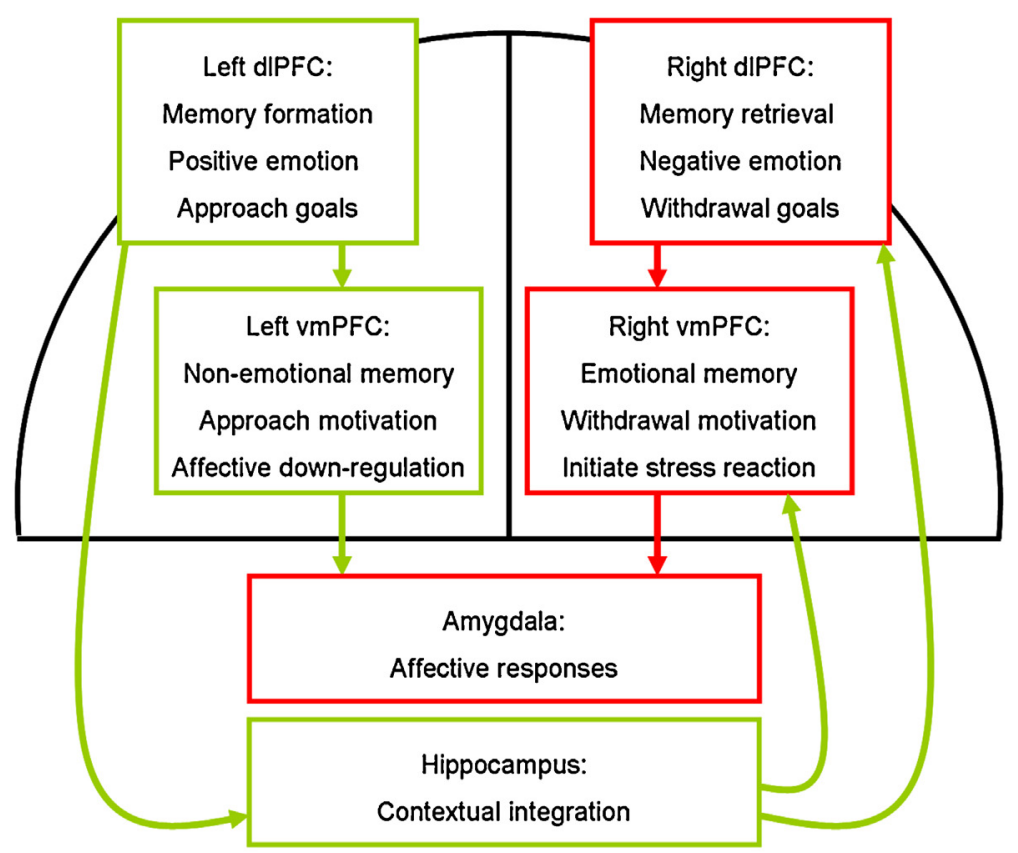

c)

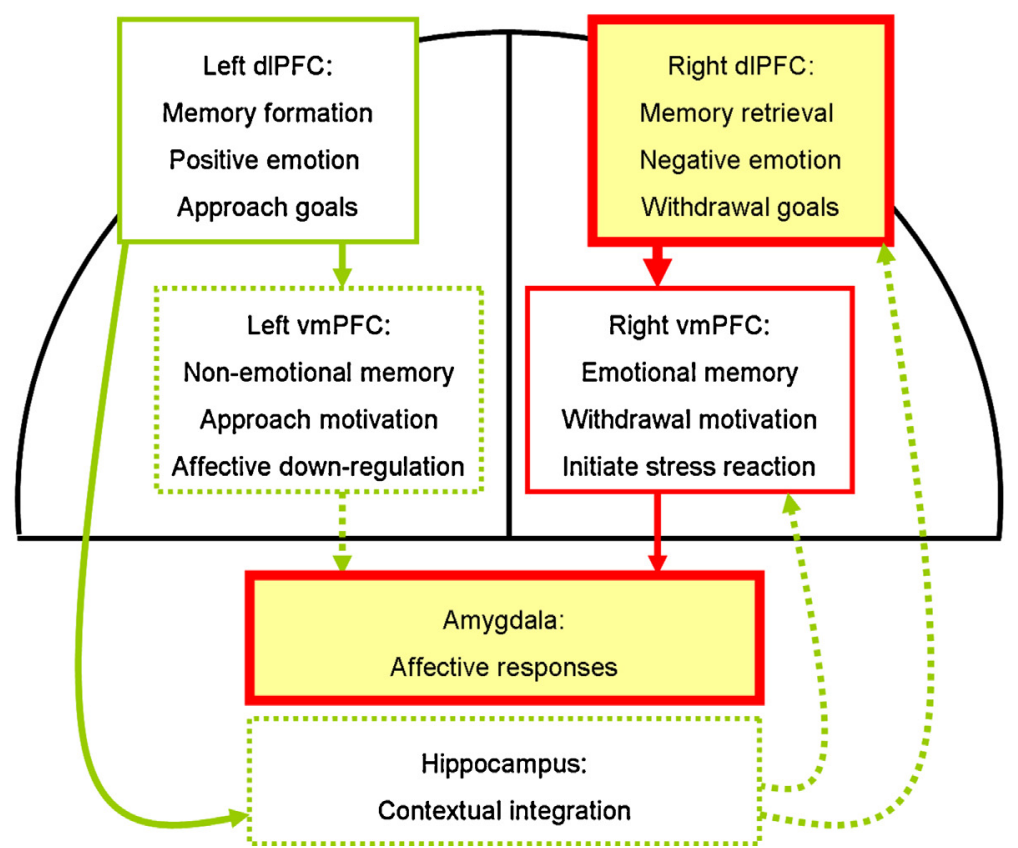

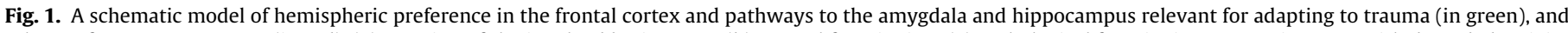

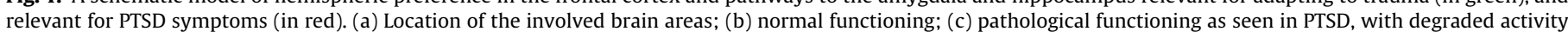

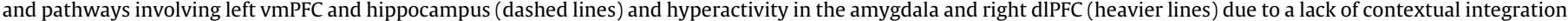

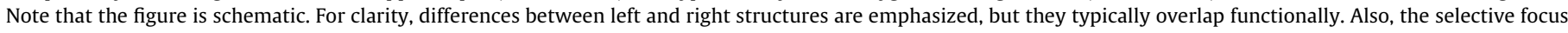
on functions, regions, asymmetries, and one-directional pathways necessarily omits others that can be of interest. 
emotional processes, such as the allocation of attention to threatening stimuli, has been shown to be associated with lateral PFC activation (Browning, Holmes, Murphy, Goodwin, \& Harmer, 2010).

Regarding lateralization, findings suggest that reappraisal strategies primarily rely on the left PFC, although this could be moderated by the goal (e.g., increase or decrease emotions) and content (e.g., negative or positive emotion) of the reappraisal task (Ochsner \& Gross, 2005). For instance, one study found primarily left-sided PFC activation when participants dampened their negative emotional reactions (Ochsner, Bunge, Gross, \& Gabrieli, 2002), whereas another study found more right-sided PFC activation in participants dampened their reactions to erotic stimuli (Beauregard, Levesque, \& Bourgouin, 2001). Notably, the first study also involved a more verbal reappraisal strategy than the second. Thus, left-sided frontal activation might reflect reappraisal with a hedonic goal, as well as recruitment of lateralized structures involved in verbal and non-verbal stimulus processing (Ochsner et al., 2002). Importantly, these findings still await replication and a direct statistical test of lateralization. Yet, a recent EEG study supports the association between left-frontal activation and reappraisal. In particular, Parvaz, MacNamara, Goldstein, and Hajcak (2012) showed that cognitive reappraisal during positive and negative picture viewing was associated with reduced event-related alpha power (which could be interpreted as increased activation) over the left forehead. Thus, state-dependent frontal asymmetry may be indicative of engagement in cognitive reappraisal by reflecting the differential recruitment of the left and right dIPFC.

The involvement of the left and right dIPFC in emotional processing has been further documented in studies using repetitive transcranial magnetic stimulation (rTMS). rTMS can be used to interfere with cortical activity using strong and repetitive magnetic pulses, whereby different pulse frequencies can either reduce (low frequencies) or increase (high frequencies) the neuronal excitability of a target cortical region. With this technique, researchers have shown that enhanced right, but not left, dlPFC excitability leads to impaired inhibition of negative emotional information (Leyman, De Raedt, Vanderhasselt, \& Baeken, 2009). Increased left dlPFC excitability was found to enhance the processing of positive emotional information while additionally attenuating insula responses to negative emotional information (Baeken et al., 2011a). Also, there are indications that when right dIPFC excitability is enhanced, more stress hormones are released when state anxiety levels are high, whereas left dIPFC stimulation can attenuate the stress response (Baeken, Vanderhasselt, \& De Raedt, 2011b; Baeken et al., 2014).

\subsubsection{Memory}

Other neuroimaging findings suggest that the left and right dIPFC play differential roles in memory. In particular, during formation of a memory trace for simple verbal or visual stimuli, the left dIPFC is preferentially activated as compared to the right dIPFC, whereas the opposite pattern has been observed during retrieval of such a memory (Habib, Nyberg, \& Tulving, 2003; Henson, Rugg, Shallice, \& Dolan, 2000). The right PFC appears to reflect specific monitoring processes that occur directly after the retrieval of recently acquired memories (for review, see Gilboa, 2004) and is recruited especially in more difficult recall tasks (Fletcher \& Henson, 2001; Henson et al., 2000) or when recognition depends on contextual information (King, Hartley, Spiers, Maguire, \& Burgess, 2005).

Recent rTMS studies appear to correspond with the view that the left dIPFC is crucial for encoding or consolidation of new memories, whereas the right dlPFC is crucial for memory retrieval. For instance, recognition memory for pictures and words is impaired when TMS interferes with the left dIPFC during post-perceptual processing of to-be-learned pictures (i.e., $300 \mathrm{~ms}$ after picture onset; Rossi et al., 2011). Likewise, rTMS stimulation of the right
dlPFC following encoding (Turriziani et al., 2012) or following cued memory reactivation (Sandrini, Censor, Mishoe, \& Cohen, 2013) can enhance memory performance, whereas stimulation of that site during retrieval can impair performance (Sandrini, Cappa, Rossi, Rossini, \& Miniussi, 2003). However, further replications are warranted, as the few existing studies diverge on several parameters, including the TMS protocols, time of stimulation, and targeted memory phases. Also, more studies are needed to identify potential moderators in the encoding-retrieval asymmetry, including verbalization (Epstein, Sekino, Yamaguchi, Kamiya, \& Ueno, 2002), retrieval strategies (Manenti, Cotelli, Calabria, Maioli, \& Miniussi, 2010), or retrieval facilitation (Sandrini et al., 2003).

Taken together, fMRI and rTMS studies seem to support the view that the left and right dlPFC are differentially involved in cognitive emotion regulation, emotional processing, and in memory processes. In particular, more left-sided activity appears to be associated with positive emotion, down-regulation of negative emotion, and memory encoding, as opposed to negative emotion, down-regulation of positive emotion, and memory retrieval. Furthermore, and in line with studies that have linked frontal EEG asymmetry to stress responding (e.g., Buss et al., 2003; Hewig et al., 2008; Lewis et al., 2007; Quaedflieg et al., 2015), rTMS studies suggest that activation of the right dIPFC facilitates the initiation of hormonal stress responses, whereas activation of the left counterpart might dampen these responses. The emotion- and memory-related asymmetries could be additive or interact with each other (see, e.g., Weigand et al., 2013). Accordingly, relatively left-sided dIPFC activity would be expected to have favorable consequences for coping with trauma.

\subsection{Left and right medial PFC and amygdala}

\subsubsection{Approach and withdrawal reactions}

Davidson $(1998,2000)$ proposed that important contributions to frontal asymmetry might originate from activations within a larger network including the temporal polar regions, amygdale, basal ganglia, and hippocampi. Accordingly, within such a network, approach and withdrawal motivations are represented in the lateral PFC as goal states held in working memory. These goals are transferred to medial prefrontal structures that play a central role in keeping behavioral-reinforcement contingencies in working memory. From there, approach-related information is transmitted to the nucleus accumbens and to the basal ganglia to coordinate and execute action plans, whereas goals related to withdrawal motivation critically involve the amygdala.

Indeed, there appear to be several lateralized regions within the medial PFC that are consistently activated during manipulations of motivational direction (Wager, Phan, Liberzon, \& Taylor, 2003). In line with the motivational direction model of frontal asymmetry, asymmetric activation within the medial PFC during cognitive task performance has been found to predict trait motivational direction (Spielberg et al., 2011). Furthermore, animal studies suggest that autonomic and neuroendocrine reactions to stress predominantly implicate the right vmPFC (Cerqueira, Almeida, \& Sousa, 2008; Sullivan \& Gratton, 2002). In particular, the right vmPFC appears to be responsible for hormonal stress responses, stress ulcer formation, and stress-induced deterioration of the connection between the frontal cortex and the hippocampus (Cerqueira et al., 2008; Cerqueira, Mailliet, Almeida, Jay, \& Sousa, 2007).

In humans, direct tests of lateralization in the vmPFC and amygdala are still warranted. Still, the view that left-sided activity in both vmPFC and the basal ganglia accounts for the association between left-sided frontal activity and approach motivations has been supported in fMRI studies (Spielberg et al., 2011, 2012). Therefore, it may well be the case that both right-lateralized vmPFC and amygdala activity, and left-sided activity in the vmPFC and 
Table 5

Summary of brain processes possibly contributing to frontal asymmetry and PTSD symptoms.

\begin{tabular}{|c|c|c|c|c|c|}
\hline \multirow[t]{2}{*}{ Region } & \multicolumn{2}{|l|}{ Preferential hemispheric function } & \multirow{2}{*}{$\begin{array}{l}\text { Consequence of frontal asymmetry } \\
(\alpha \mathrm{L}<\alpha \mathrm{R})\end{array}$} & \multicolumn{2}{|c|}{ Key references } \\
\hline & Left & Right & & First author & Year \\
\hline \multirow[t]{8}{*}{ dlPFC } & \multirow[t]{2}{*}{ Memory formation } & \multirow{2}{*}{$\begin{array}{l}\text { Memory retrieval and monitoring, } \\
\text { use of contextual information }\end{array}$} & \multirow{2}{*}{$\begin{array}{l}\text { Reduced preoccupation with memories } \\
\text { in favor of memory formation }\end{array}$} & Fletcher & 2001 \\
\hline & & & & Habib & 2003 \\
\hline & \multirow{3}{*}{$\begin{array}{l}\text { Cognitive reappraisal with } \\
\text { possible preference of verbal } \\
\text { and hedonic strategies }\end{array}$} & \multirow{3}{*}{$\begin{array}{l}\text { Cognitive reappraisal with possible } \\
\text { preference of non-verbal and } \\
\text { non-hedonic strategies }\end{array}$} & \multirow{3}{*}{$\begin{array}{l}\text { Facilitated cognitive regulation of } \\
\text { negative emotions }\end{array}$} & Beauregard & 2001 \\
\hline & & & & Ochsner & 2002 \\
\hline & & & & Parvaz & 2012 \\
\hline & \multirow{2}{*}{$\begin{array}{l}\text { Facilitation of positive emotion } \\
\text { processing }\end{array}$} & \multirow{2}{*}{$\begin{array}{l}\text { Facilitation of negative emotion } \\
\text { processing }\end{array}$} & \multirow{2}{*}{$\begin{array}{l}\text { More experience of positive emotions; } \\
\text { reduced or more efficient negative } \\
\text { emotion processing }\end{array}$} & Baeken & 2011 \\
\hline & & & & Leyman & 2009 \\
\hline & Approach actions & Withdrawal actions & $\begin{array}{l}\text { Increased approach behavioral } \\
\text { tendencies }\end{array}$ & Berkman & 2010 \\
\hline \multirow[t]{6}{*}{ vmPFC } & \multirow{2}{*}{$\begin{array}{l}\text { Down-regulation of the } \\
\text { amygdala }\end{array}$} & \multirow{2}{*}{$\begin{array}{l}\text { Controlling hormonal stress } \\
\text { responses, up-regulation of } \\
\text { amygdala }\end{array}$} & \multirow{2}{*}{$\begin{array}{l}\text { Reduced negative information } \\
\text { processing; more efficient control of } \\
\text { autonomic stress responses }\end{array}$} & Greenberg & 2005 \\
\hline & & & & Sullivan & 2002 \\
\hline & \multirow{2}{*}{$\begin{array}{l}\text { Processing of non-emotional } \\
\text { memories }\end{array}$} & \multirow{2}{*}{$\begin{array}{l}\text { Processing emotional } \\
\text { autobiographical memories, } \\
\text { contextual integration }\end{array}$} & \multirow[b]{2}{*}{$\begin{array}{l}\text { Reduced preoccupation with trauma } \\
\text { memories; less or more efficient } \\
\text { association with emotion and } \\
\text { contextual integration via } \\
\text { hippocampus }\end{array}$} & Cabeza & 2007 \\
\hline & & & & Cerqueira & 2008 \\
\hline & Approach motivation through & Withdrawal motivation through & Increased approach, decreased & Davidson & 1998 \\
\hline & connection with basal ganglia & connection with amygdala & withdrawal motivation & Spielberg & 2012 \\
\hline \multirow[t]{2}{*}{ Amygdala } & \multirow[t]{2}{*}{ Controlled emotional reactions } & \multirow{2}{*}{$\begin{array}{l}\text { Automatic emotional reactions; } \\
\text { negative memory formation } \\
\text { through right parahippocampus, } \\
\text { vmPFC }\end{array}$} & \multirow{2}{*}{$\begin{array}{l}\text { Dampened initiation of stress } \\
\text { responses; more efficient control of } \\
\text { stress responses; reduced negative } \\
\text { memory formation }\end{array}$} & Dyck & 2011 \\
\hline & & & & Kilpatrick & 2003 \\
\hline
\end{tabular}

Note. $\alpha \mathrm{L}=$ alpha power over the left frontal cortex; $\alpha \mathrm{R}=$ alpha power over the right frontal cortex.

the basal ganglia contribute to scalp recordings of frontal asymmetry. Together, this might partly account for the associations between frontal asymmetry and stable or transient withdrawal and approach motivations. Of course, this interpretation remains speculative, because EEG recordings mostly reflect cortical activity, and lateralization in sub-cortical brain areas might not or even be reversely linked to frontal asymmetry as measured with EEG (for discussion, see Ahern et al., 2001).

\subsubsection{Emotional memory}

In addition, preliminary evidence suggests more right-sided medial PFC activation during the processing of emotional autobiographical memories, compared to non-emotional memory processing (Cabeza \& St Jacques, 2007; Svoboda, McKinnon, \& Levine, 2006). Moreover, right vmPFC activation during negative memory retrieval was found to correlate with amygdala activity (Greenberg et al., 2005). Data also suggests that the left and right amygdale differently modulate memory, depending on specific emotional states. For instance, a positron emission tomography (PET) study using emotionally provocative films (Kilpatrick \& Cahill, 2003) found that enhanced right amygdala activation correlated with enhanced memory of the films, possibly because it modulates activity in the right parahippocampal gyrus and vmPFC. A reason why the right amygdala might be more involved in emotional memory than the left could be that the right amygdala is preferentially responsive during automatic, compared to controlled, emotional states (e.g., Dyck et al., 2011; though also see McMenamin \& Marsolek, 2013).

In sum, enhanced right-sided activity in the vmPFC and amygdala might reflect increased processing of negative information and emotional memory, as well as facilitated initiation of automatic stress responses. Table 5 provides a summary of the abovementioned considerations. Fig. 1 displays the principal brain regions and sketches their relevant functions. In addition, the figure includes hypothetical pathways among these brain regions that may contribute to PTSD symptoms that we outline in the following section.

\section{Frontal asymmetry and PTSD: A neurocircuitry perspective}

\subsection{Neuroimaging findings in PTSD}

Neuroimaging research on PTSD has focused most intensively on the amygdala, the hippocampus, and the prefrontal cortex (Francati, Vermetten, \& Bremner, 2007; McNally, 2006; Shin, Rauch, \& Pitman, 2006). In their review of the extant literature, Shin et al. (2006) concluded that altered functioning of these brain regions is a relatively reliable finding in PTSD (cf. Francati et al., 2007; Patel, Spreng, Shin, \& Girard, 2012). In particular, PTSD patients typically display more amygdala activity in response to traumarelevant stimuli than controls, whereas activity in the medial PFC is reduced. Meanwhile, a volumetric reduction of PTSD patients' hippocampi has often been found (O'Doherty, Chitty, Saddiqui, Bennett, \& Lagopoulos, in press), along with excessive activation in these structures across a wide range of tasks (Patel et al., 2012). This pattern of neuronal responding might distinguish PTSD from other anxiety disorders (Etkin \& Wager, 2007) and appears to be in part a predisposing factor for the development of PTSD and in part a consequence of traumatic experiences (van Wingen, Geuze, Vermetten, \& Fernandez, 2011).

These findings can be explained by considering the vmPFC and the amygdala as a core affect network that regulates emotional responses. By default, the amygdala responds to emotionally salient stimuli, but is inhibited by the vmPFC in a context-dependent manner (Suvak \& Barrett, 2011; Thayer, Ahs, Fredrikson, Sollers, \& Wager, 2012). The vmPFC is regarded as a key structure for integrating internal and external representations of the situational context, autobiographical memory, emotional appraisals, and the regulation of behavioral and physiological responses (Svoboda et al., 2006; Thayer et al., 2012). The inhibitory control of the vmPFC on the amygdala therefore depends on memory and cognitive appraisals (e.g., the experience of cognitive control; Maier \& Watkins, 2010). In PTSD, the reduced vmPFC activity has been proposed to reflect decreased control of bodily responses, which disinhibits the default amygdala responses to threat and thereby 
produces states of hypervigilance (Suvak \& Barrett, 2011; Thayer et al., 2012). This mechanism would also underlie the specific sensitization of the amygdala to trauma-related stimuli (Francati et al., 2007).

This hypothesis is supported by recent findings in police officers showing that resilience to traumatic experiences and better recovery from PTSD are marked by enhanced vmPFC and reduced amygdala activity during trauma memory retrieval (Peres et al., 2011). However, some conflicting evidence exists. That is, during negative (not traumatic) memory retrieval, PTSD patients were found to display exaggerated VmPFC activity that was coupled with higher amygdala responsivity (St Jacques, Botzung, Miles, \& Rubin, 2011). Also, vmPFC damage can reduce, rather than increase, the risk of developing PTSD (for a review, see Koenigs \& Grafman, 2009). This suggests a crucial importance of moderating factors in the relationship of the vmPFC and the amygdala, such as contextual memory. For instance, the functionality of the vmPFC may depend on appropriate input from the hippocampus, which also shows abnormal responsivity in patients with PTSD. While the vmPFC appears to play a key role in PTSD through its involvement in a memory-guided core affect network, other PFC subregions may also be involved in PTSD through their involvement in neuronal networks for executive attention, language, and for embedding traumatic memories meaningfully with other memories (Suvak \& Barrett, 2011).

\subsection{Asymmetries in the neurocircuitry of PTSD}

\subsection{1. $d l P F C$}

Considering the left and right dIPFC as a major source of frontal asymmetry, it is possible that these regions exert differential effects on the vmPFC via their involvement in cognitive emotion regulation (Ochsner \& Gross, 2005). According to that view, the inability of the vmPFC to inhibit the amygdala in PTSD could in part be a down-stream effect of inefficient cognitive control by the dlPFC.

While left and right dIPFC involvement in PTSD has not yet been addressed explicitly, a few studies using response inhibition or working memory tasks reported simple effects of aberrant left, right, or bilateral dIFPC activities in PTSD. For instance, Fani et al. (2012) found that PTSD patients display enhanced left dIPFC activation when confronted with threat-related distractors during a selective attention task, compared to conditions involving neutral or positive distracters. Moreover, this exaggerated activation correlated positively with PTSD symptoms. Meanwhile, a PET study by Clark et al. (2003) found that PTSD patients had deficient activation of the left dlPFC compared to controls during a task requiring working memory updating. These findings coincide with the findings of Dolcos et al. (2013), who showed that the left dlPFC is responsive to emotional distraction and might mediate impairments in taskrelevant executive control. Another fMRI study found PTSD patients to display lower right dIPFC activation than healthy and traumaexposed controls in a response inhibition task with neutral stimuli (Falconer et al., 2008). Here, frontal activation inversely correlated with PTSD symptoms. Finally, other findings indicate that PTSD patients display bilateral dIPFC hyperactivity associated with the maintenance of verbal stimuli in working memory (Moores et al., 2008).

The importance of further investigating dlPFC asymmetries in PTSD is pointed out by studies linking them to other emotional disorders. For instance, using fMRI, abnormal asymmetric activations of the dlPFC have been found in depressed patients during an emotional judgment task (Grimm et al., 2008). In this study, patients showed hyperactivity in the right dIPFC that correlated with depression severity, and hypoactivity in the left dIPFC. Moreover, decreasing right dIPFC excitability with rTMS has been found to boost exposure therapy effects for depression (Chen et al., 2013), as well as PTSD (e.g., Osuch et al., 2009; for a review, see Pallanti \& Bernardi, 2009; see also Tillman et al., 2011).

Together, there are good indications that PTSD is marked by inefficient dIPFC functioning, such that emotional distractors lead to an excessive deployment of cognitive resources, which, in turn, impairs efficient processing of neutral stimuli in working memory. With respect to asymmetry, the available data in PTSD patients suggest that especially the left dIPFC might be sensitive to disruption by emotional stimuli. Notably, studies explicitly testing laterality are still required, and the precise mechanisms by which dlPFC asymmetries are related to PTSD symptoms and frontal EEG asymmetry still await empirical scrutiny.

\subsection{2. $v m P F C$ and amygdala}

There is also evidence suggesting that asymmetric vmPFC and amygdala dysfunctions are present in PTSD. Some, but not all symptom provocation studies with PTSD patients found enhanced right-sided activation of the amygdala (Francati et al., 2007). This activation might reflect enhanced encoding of negative emotional memories through modulation of the right parahippocampal gyrus and vmPFC (Kilpatrick \& Cahill, 2003). In line with this view, the right parahippocampus has frequently been found to be hyperactivated in PTSD (Patel et al., 2012). Moreover, one study found resting state functional connectivity patterns of the right amygdala with the posterior cingulate and the perigenual anterior cingulate cortices to be associated with PTSD symptoms (Lanius et al., 2010). These latter areas are thought to be involved in various functions such as monitoring sensory input, self-referential processing, and the conscious experience of emotion (Bluhm et al., 2009; Vogt, Finch, \& Olson, 1992).

Also, as mentioned earlier, PTSD may be marked by exaggerated functional coupling between the amygdala and the vmPFC during retrieval of negative emotional memories (St Jacques et al., 2011). Furthermore, the right vmPFC is especially implicated in the processing of emotional autobiographical memory, contextual integration, and the control of ANS responses to stress. Thus, heightened right-sided activity in the vmPFC might make individuals more vulnerable to the negative effects of stress, lead to impaired contextual integration of trauma memories, and thereby undermine their stress resilience.

\subsection{Summary}

Our review shows that frontal asymmetry might be related to individual differences in cognitive emotion regulation and memory-relevant processes mediated by the dlPFC. As well, it could reflect individual differences in emotional responding and biased memory formation mediated by the vmPFC and the amygdala. Together, it appears plausible that frontal asymmetry partly reflects the efficiency of the PFC to regulate the amygdala in a memoryguided and context-dependent manner. The hippocampus is a key structure for the contextual integration of emotional memory, and its pathways to the right vmPFC and dIPFC may be essential for the inhibition of withdrawal and stress responses. As Fig. 1 displays (see panel c), poor functioning of these connections may increase the risk of developing PTSD symptoms. Thus, frontal asymmetry may reflect individual differences in neural networks and psychological mechanisms that are involved in the complex causation of PTSD.

\section{Discussion}

In this article, we aimed to explore whether and how frontal asymmetry may be related to individual differences in adjustment to traumatic experiences and, in particular, whether it may serve as 
a biomarker of PTSD. Trait and state frontal asymmetry have been related to current and lifetime depression and anxiety disorders. PTSD shares fear-related symptoms with other anxiety disorders, dysphoria-related symptoms with depression, and general distress symptoms with both types of disorder. On this basis, it is conceivable that frontal asymmetry plays a role in PTSD as well. However, our review revealed that the empirical evidence for this link is still weak. Trait right-sided frontal activity was associated with more PTSD symptoms in only one of eight studies, while asymmetric frontal activation during trauma cue exposure predicted PTSD symptoms in two studies. More research is clearly warranted, and it may be particularly beneficial for future studies to address methodological weaknesses of the available studies, as we discuss further below.

We also explored how the neural origins of frontal asymmetry might be related to the neurocircuitry of PTSD. In particular, frontal asymmetry has been proposed to reflect differential hemispheric activity in specific brain regions, including the left and right dIPFC, vmPFC, and the amygdala. These brain regions are usually implicated in cognitive emotion regulation, memory, and automatic affective responding, and have also been found to function abnormally in PTSD patients. Although neuroimaging studies rarely performed explicit tests of laterality, several plausible links emerge between relatively right-sided frontal asymmetry and the neurocircuitry of this disorder (see Fig. 1 and Table 5).

\subsection{Methodological issues}

Importantly, the studies included in our review have methodological weaknesses that merit comment. Trait frontal asymmetry correlated with PTSD symptoms only in one study, and within this study only in the PTSD patient subgroup ( $n=14$; Kemp et al., 2010). Notably, besides a smaller sample size than the other studies (see Tables 1 and 2), this study also had the shortest recording period. This is a potential weakness, since shorter recording periods decrease the trait specificity of the resting state measure (Hagemann, 2004). Interestingly, however, a meta-analysis by Thibodeau et al. (2006) found that length of EEG recording was negatively associated with the effect size for the relationship between frontal asymmetry and depression. This suggests that trait frontal asymmetry correlates with psychopathology especially when the measurement is more prone to contamination by state influences in the laboratory, such as negative mood shifts due to the EEG preparation, the sex of the experimenter, or the time of day and the time of year (Hagemann, 2004; Velo, Stewart, Hasler, Towers, \& Allen, 2012). The potentially moderating role of these factors still remains to be addressed in future research.

Also other methodological variations may have affected the trait frontal asymmetry results. In particular, length of EEG recording and recording sites used to derive frontal asymmetry varied considerably between studies, as did some of the sample characteristics (e.g., gender ratio). Relatedly, the current review included studies from only four entirely independent research programs. That is, three studies were from the same research group, whereas three other publications used parts of a common participant database. As a consequence, some of the included publications are based on overlapping participant samples (see Table 1), warranting additional caution in generalizing the results. Similarly, the conclusions regarding state-dependent frontal asymmetry are limited by the fact that all findings come from a single laboratory and are based on partly overlapping samples. Once more, these considerations underscore the necessity of additional studies in traumatized samples to advance this line of research.

\subsection{Resting frontal asymmetry as a marker of PTSD}

Our findings seem to indicate that trait frontal asymmetry cannot serve as a reliable biomarker of PTSD. Notably, this conclusion could be premature. Instead, it is possible that the strong heterogeneity of symptoms could have overshadowed potential effects, as well as the typically high level of comorbidity that we also found in the included studies (see Table 1). In line with this, Thibodeau et al. (2006) found that right-sided frontal activity indeed characterizes patients with depression or with an anxiety disorder, but lower correlations were found in patients with comorbid anxiety and depression. Thus, the complex clinical picture of PTSD, which features symptoms of both anxiety and depression, may have reduced the correlation patterns in research on frontal asymmetry.

According to this line of reasoning, different PTSD symptom clusters may be differentially associated with trait frontal asymmetry. For instance, the motivational direction model of frontal asymmetry (Davidson, 1998) would predict fearrelated symptoms to be associated with exaggerated withdrawal motivation and hence, with increased right-sided activity. Similarly, dysphoria-related symptoms could be related to deficient approach motivation and decreased left-sided activity. Meanwhile, avoidance-related symptoms could have an ambivalent relationship with frontal asymmetry. That is, these symptoms may be driven by motivations to withdraw (i.e., fear) on the one hand, and on the other hand, by approach-related goals subserving an active avoidance strategy. Finally, it is still unclear how frontal asymmetry might be related to dissociative amnesia and flashbacks, which are symptoms that may uniquely distinguish PTSD from other mental disorders (Brewin, 2011; Bryant et al., 2011).

In addition to the broad symptom clusters, an important observation might be that traumatized individuals often display exaggerated anger or related emotions, such as bitterness and erroneous self- or other blame. These reactions often lead to reckless, aggressive, and maladaptive behavior and have a major impact on post-traumatic adjustment (Friedman, Resick, Bryant, \& Brewin, 2011; Linden, Baumann, Rotter, \& Schippan, 2008; McHugh, Forbes, Bates, Hopwood, \& Creamer, 2012). Importantly, both state and trait anger are marked by approach motivation and have been associated with left-sided frontal activity (Harmon-Jones et al., 2010). In other words, extreme approach and withdrawal tendencies can coexist in PTSD, and this may be expressed in opposing patterns of frontal asymmetry. Since approach and withdrawal tendencies are thought to transiently suppress each other (Schutter \& Harmon-Jones, 2013), anger-related symptoms might dampen or reverse frontal asymmetry in resting state measurements. Thus, on the one hand, future studies should explicitly take anger-related symptoms into account. On the other hand, it appears generally advisable to control for transient motivations in measurements of frontal asymmetry, implying that state-dependent measures might be preferable over resting state measures. Related to this, future research might try to address the flow of the causal directions in frontal asymmetry. That is, would activity asymmetries be driven by increased use of cognitive functions in one hemisphere or by impaired or inefficient processing in the other hemisphere? By making such issues explicit, theories concerning frontal asymmetry and the hypotheses formulated in this review (see Table 5) would become more testable.

Finally, it is worth mentioning that a number of other factors might moderate the association between frontal asymmetry and PTSD. For instance, trauma type and severity affect peritraumatic stress and risk perception (Grimm, Hulse, Preiss, \& Schmidt, 2012) and can change the course of the disorder (Brewin et al., 2000). According to McNally and Robinaugh (2011), trauma type and severity might also make individual risk and resilience 
factors more or less important in determining mental health outcomes. This might also apply to the association between frontal asymmetry and PTSD. Suggestive support for this view comes from a recent study using trauma films (Meyer et al., 2014), in which we found that frontal asymmetry is associated with startle responses to film cues, but size and direction of this effect was moderated by the type of trauma film. Taken together, more controlled studies of frontal asymmetry in relation to more specific patient groups, symptom clusters and underlying factors (e.g., depression, anxiety, and anger), as well as transient states are both promising and pressingly needed (for similar discussions, see Bonanno, Westphal, \& Mancini, 2011; Van Praag et al., 1990).

\subsection{State-dependent frontal asymmetry and PTSD}

The findings reported by Rabe et al. (2006a, 2008) suggest that PTSD patients might be characterized by an abnormal right-sided frontal activation in response to trauma-related stimuli, but not to unrelated negative stimuli or activity at rest. This pattern is reminiscent of the finding that many PTSD patients display abnormally strong startle responses, specifically to trauma-related stimuli (Orr \& Roth, 2000), which is indicative of enhanced amygdala activation (Davis, Walker, \& Lee, 1997). Thus, right-sided frontal activation in response to trauma-related stimuli might be a down-stream effect of exaggerated negative information processing, as well as autonomic and neuroendocrine stress reactions mediated by the right vmPFC and amygdala (Cerqueira et al., 2008; Greenberg et al., 2005).

Should future studies corroborate these findings, then practical implications can be envisioned: state-dependent frontal asymmetry in response to trauma-related cues could serve as a biological marker of PTSD symptoms. Consequently, a next step would be to investigate how this measure can be optimized for diagnostic purposes. Rabe and colleagues found associations between PTSD symptoms and frontal asymmetry when participants were exposed to a relevant stimulus (i.e., an image of a car accident) that activated memories of trauma (motor vehicle accidents). This was not found with a trauma-unrelated negative stimulus (i.e., an image of a barking dog). Thus, it remains to be seen whether asymmetric activation in response to other (e.g., stronger) negative stimuli that are not (yet) idiosyncratically linked to a traumatic event could predict PTSD. As well, future research will need to explore the sensitivity and specificity of the elicited asymmetric responses to PTSD. That is, more right-sided frontal activation in response to emotional challenges is also evident in patients with depression (Stewart, Coan, Towers, \& Allen, 2011) and panic disorder (Wiedemann et al., 1999), suggesting that this could be a transdiagnostic marker of emotional symptoms. Therefore, a more fine-grained analysis of the specific symptom clusters that are associated with state-dependent frontal asymmetries would be informative.

A related and similarly important route for future research is to explore the role of frontal asymmetry in trauma-related symptoms that are specific to PTSD, such as flashbacks and dissociative amnesia (Brewin, 2011; Bryant et al., 2011). Extending the procedure by Rabe et al. (2006a), studies could integrate some of the methods that are commonly used in trauma-memory research, including various forms of trauma cue exposure (e.g., Bremner et al., 1999; McCaffrey et al., 1993), script-driven imagery (e.g., Hopper, Frewen, van der Kolk, \& Lanius, 2007), or writing and reading trauma narratives (e.g., Hellawell \& Brewin, 2002). As well, analogue studies that use the trauma-film paradigm in healthy participants (Holmes \& Bourne, 2008) can help to establish a link between right-sided activation during memory processing and affective responses under controlled circumstances (e.g., Chou, La Marca, Steptoe, \& Brewin, 2014; Meyer et al., 2013, 2014). Jointly, these paradigms can address whether provocation-induced frontal asymmetry plays different roles in various forms of trauma memory, such as involuntary or intrusive memories, flashbacks, and voluntarily retrieved memories. Importantly, this requires researchers to explicitly define the type of trauma memory that they aim to measure (for discussion, see Brewin, 2014; Kvavilashvili, 2014; Meyer, Otgaar, \& Smeets, 2015). As well, it would be informative to assess or manipulate emotion regulation strategies in response to trauma memories (e.g., emotional or expressive suppression), because these might influence associations with frontal asymmetry (Harmon-Jones et al., 2010).

\subsection{Other promising avenues for frontal asymmetry research}

Several recent advances in the field of frontal asymmetry research that could notably benefit the study of this potential marker of psychopathology deserve to be mentioned. One promising route for future research is to refine the measurement of frontal asymmetry. For instance, Allen and Cohen (2010) measured short bursts of alpha asymmetry instead of averaging alpha power across several minutes. This way, the authors aimed to increase the temporal specificity of the asymmetry metric, which could eventually help to understand the neuropsychological underpinnings of frontal asymmetry and to better link it to neuroanatomical data. Others have focused on individual alpha frequencies (IAF; typically ranging from 9.5 to $11.5 \mathrm{~Hz}$ in young healthy adults; Klimesch, 1999) for deriving alpha asymmetry scores, rather than using the broader alpha frequency band from 8 to $13 \mathrm{~Hz}$ (e.g., Quaedflieg et al., 2015; Segrave et al., 2011). Similarly, it might be beneficial to investigate frontal asymmetry separately in two alpha subbands, since desynchronization in the lower alpha range (below IAF) has been suggested to reflect attentional processes, whereas desynchronization in the upper alpha range (above IAF) might reflect cognitive activity (Klimesch, 1999). Finally, with the rapidly advancing understanding of the functional significance of neuronal oscillations in brain networks (Buzsaki \& Draguhn, 2004; Klimesch et al., 2007), it may become increasingly interesting to consider frontal asymmetry in the alpha band in relation to (lateralized) synchronization in other bands (e.g., asymmetric gamma activity might be related to memory processes; Babiloni et al., 2006; activity in the theta band might reflect limbic activity; Klimesch, 1999; for discussion, also see Miller, Crocker, Spielberg, Infantolino, \& Heller, 2013).

More generally, and as suggested by Davidson (2004), this type of research will likely benefit from combining EEG with other cognitive neuroscience techniques by elucidating the more detailed neuronal basis of asymmetric electrical signals, and from interventions that help in understanding the causal role of frontal asymmetry in emotion. As we stated in our review, non-EEG neuroimaging studies often omit explicit tests of laterality. Adding these would clearly help to advance our understanding of brain asymmetry. For most brain functions, we would not expect research to identify a distinctive "division of labor" between the two hemispheres, because homologous structures in the two hemispheres typically show functional overlap. Still, laterality effects can be highly meaningful and are worth exploring further. One type of study that has already provided valuable insights about lateralized brain functions and emotion processing is using rTMS as an intervention to (asymmetrically) change brain activity (e.g., Baeken et al., 2014).

Another promising intervention technique is EEG neurofeedback, in which parameters of the brain's electrophysiology are used as the basis for real-time feedback to the participant. By this feedback, individuals undergoing neurofeedback learn to selfregulate specific patterns of their brain physiology. Neurofeedback has already been used to change frontal asymmetry, but the impact 
of this on different emotional responses remains to be evaluated empirically (cf. Allen, Harmon-Jones, \& Cavender, 2001; Peeters, Ronner, Bodar, van Os, \& Lousberg, 2014). Yet, case studies (Baehr, Rosenfeld, \& Baehr, 1997; Baehr, Rosenfeld, \& Baehr, 2001) and a randomized treatment trial in depression (Choi et al., 2011) suggest that this approach may be beneficial in the therapy of emotional disorders.

\section{Conclusions}

A large and growing body of literature suggests that both state-dependent and trait frontal asymmetries can be informative markers related to depression and anxiety disorders, suggesting high relevance for PTSD. However, as we show in our review, surprisingly few studies have directly addressed the relationship between frontal asymmetry and PTSD. Methodological limitations of these studies aside, trait frontal asymmetry appears little if any predictive value with respect to PTSD symptoms. Meanwhile, initial findings point out that asymmetric frontal activation after traumarelevant stimulation is a potential biomarker of PTSD symptoms. In addition, we showed that asymmetric activation in the dIPFC, vmPFC, and amygdala can be plausibly linked to abnormal psychological and brain functions thought to be responsible for PTSD. We thus formulated a set of new hypotheses concerning the neural processes that may connect state-dependent and trait frontal asymmetry to psychological adjustment after trauma and suggest that neuroimaging studies should more explicitly address lateralization effects in their statistical analyses. For future studies on EEG asymmetry and PTSD, we suggest focusing on specific symptom clusters, particularly anxiety, dysphoria, and anger-related symptoms, and thus to explore the potential of frontal asymmetry more as a transdiagnostic marker of pathological adjustment. At the same time, it appears promising to integrate paradigms from the traumamemory field in the study of state-dependent frontal asymmetry, in order to gain more insight in the specific role of this marker in PTSD.

\section{References}

Ahern, G. L., Sollers, J. J., Lane, R. D., Labiner, D. M., Herring, A. M., Weinand, M. E., et al. (2001). Heart rate and heart rate variability changes in the intracarotid sodium amobarbital test. Epilepsia, 42, 912-921. http://dx.doi.org/10.1046/ j.1528-1157.2001.042007912.x

Allen, J. J. B., \& Cohen, M. X. (2010). Deconstructing the "resting" state: Exploring the temporal dynamics of frontal alpha asymmetry as an endophenotype for depression. Frontiers in Human Neuroscience, 4, 14. http://dx.doi.org/10.3389/ fnhum.2010.00232

Allen, J. J. B., Harmon-Jones, E., \& Cavender, J. H. (2001). Manipulation of frontal EEG asymmetry through biofeedback alters self-reported emotional responses and facial EMG. Psychophysiology, 38, 685-693. http://dx.doi.org/10.1111/ 1469-8986.3840685

Allen, J. J. B., \& Kline, J. P. (2004). Frontal EEG asymmetry, emotion, and psychopathology: The first, and the next 25 years. Biological Psychology, 67, 1-5. http://dx.doi.org/10.1016/j.biopsycho.2004.03.001

American Psychiatric Association. (2013). Diagnostic and statistical manual of mental disorders (5th ed.). Arlington, VA: American Psychiatric Publishing.

Babiloni, C., Vecchio, F., Cappa, S., Pasqualetti, P., Rossi, S., Miniussi, C., et al. (2006). Functional frontoparietal connectivity during encoding and retrieval processes follows HERA model-A high-resolution study. Brain Research Bulletin, 68, 203-212. http://dx.doi.org/10.1016/j.brainresbull.2005.04.019

Baehr, E., Rosenfeld, J. P., \& Baehr, R. (1997). The clinical use of an alpha asymmetry protocol in the neurofeedback treatment of depression: Two case studies. Journal of Neurotherapy, 2, 10-23. http://dx.doi.org/10.1300/J184v02n03_02

Baehr, E., Rosenfeld, J. P., \& Baehr, R. (2001). Clinical use of an alpha asymmetry neurofeedback protocol in the treatment of mood disorders: Follow-up study one to five years post therapy. Journal of Neurotherapy, 4, 11-18. http://dx.doi.org/10.1300/J184v04n04_03

Baeken, C., Van Schuerbeek, P., De Raedt, R., De Mey, J., Vanderhasselt, M. A., Bossuyt, A., et al. (2011). The effect of one left-sided dorsolateral prefrontal shamcontrolled HF-rTMS session on approach and withdrawal related emotional neuronal processes. Clinical Neurophysiology, 122, 2217-2226. http://dx.doi.org/ 10.1016/j.clinph.2011.04.009

Baeken, C., Vanderhasselt, M. A., \& De Raedt, R. (2011). Baseline 'state anxiety' influences HPA-axis sensitivity to one sham-controlled HF-rTMS session applied to the right dorsolateral prefrontal cortex. Psychoneuroendocrinology, 36, 60-67. http://dx.doi.org/10.1016/j.psyneuen.2010.06.006

Baeken, C., Vanderhasselt, M. A., Remue, J., Rossi, V., Schiettecatte, J., Anckaert, E., et al. (2014). One left dorsolateral prefrontal cortical HF-rTMS session attenuates HPA-system sensitivity to critical feedback in healthy females. Neuropsychologia, 57, 112-121. http://dx.doi.org/10.1016/j.neuropsychologia.2014.02.019

Beauregard, M., Levesque, J., \& Bourgouin, P. (2001). Neural correlates of conscious self-regulation of emotion. Journal of Neuroscience, 21, 6. Rc165.

Blake, D. D., Weathers, F. W., Nagy, L. M., Kaloupek, D. G., Gusman, F. D., Charney, D. S., et al. (1995). The development of a clinician-administered PTSD scale. Journal of Traumatic Stress, 8, 75-90. http://dx.doi.org/10.1007/bf02105408

Bluhm, R. L., Williamson, P. C., Osuch, E. A., Frewen, P. A., Stevens, T. K., Boksman, K., et al. (2009). Alterations in default network connectivity in posttraumatic stress disorder related to early-life trauma. Journal of Psychiatry \& Neuroscience, 34, 187.

Bonanno, G. A. (2004). Loss, trauma, and human resilience-Have we underestimated the human capacity to thrive after extremely aversive events? American Psychologist, 59, 20-28. http://dx.doi.org/10.1037/0003-066x.59.1.20

Bonanno, G. A. (2012). Uses and abuses of the resilience construct: Loss, trauma, and health-related adversities. Social Science \& Medicine, 74, 753-756. http://dx.doi.org/10.1016/j.socscimed.2011.11.022

Bonanno, G. A., \& Mancini, A. D. (2008). The human capacity to thrive in the face of potential trauma. Pediatrics, 121, 369-375. http://dx.doi.org/10.1542/ peds.2007-1648

Bonanno, G. A., Westphal, M., \& Mancini, A. D. (2011). Resilience to loss and potential trauma. In S. Nolen-Hoeksema, T. D. Cannon, \& T. Widiger (Eds.), Annual review of clinical psychology (Vol. 7) (pp. 511-535). Palo Alto, CA: Annual Reviews.

Bremner, J. D., Staib, L. H., Kaloupek, D., Southwick, S. M., Soufer, R., \& Charney, D. S. (1999). Neural correlates of exposure to traumatic pictures and sound in Vietnam combat veterans with and without posttraumatic stress disorder: A positron emission tomography study. Biological Psychiatry, 45, 806-816. http://dx.doi.org/10.1016/S0006-3223(98)00297-2

Brewin, C. R. (2011). The nature and significance of memory disturbance in posttraumatic stress disorder. Annual Review of Clinical Psychology, 7, 203-227. http://dx.doi.org/10.1146/annurev-clinpsy-032210-104544

Brewin, C. R. (2014). Episodic memory, perceptual memory, and their interaction: Foundations for a theory of posttraumatic stress disorder. Psychological Bulletin, 140, 69-97. http://dx.doi.org/10.1037/a0033722

Brewin, C. R., Andrews, B., \& Valentine, J. D. (2000). Meta-analysis of risk factors for posttraumatic stress disorder in trauma-exposed adults. Journal of Consulting and Clinical Psychology, 68, 748-766. http://dx.doi.org/10.1037| 0022-006X.68.5.748

Browning, M., Holmes, E. A., Murphy, S. E., Goodwin, G. M., \& Harmer, C. J. (2010). Lateral prefrontal cortex mediates the cognitive modification of attentional bias. Biological Psychiatry, 67, 919-925. http://dx.doi.org/10.1016/ j.biopsych.2009.10.031

Bryant, R. A., O’Donnell, M. L., Creamer, M., McFarlane, A. C., \& Silove D. (2011). Posttraumatic intrusive symptoms across psychiatric disorders. Journal of Psychiatric Research, 45, 842-847. http://dx.doi.org/10.1016/ j.jpsychires.2010.11.012

Buss, K. A., Schumacher, J. R. M., Dolski, I., Kalin, N. H., Goldsmith, H. H., \& Davidson, R. J. (2003). Right frontal brain activity, cortisol, and withdrawal behavior in 6-month-old infants. Behavioral Neuroscience, 117, 11-20. http://dx.doi.org/10.1037/0735-7044.117.1.11

Buzsaki, G., \& Draguhn, A. (2004). Neuronal oscillations in cortical networks. Science 304, 1926-1929. http://dx.doi.org/10.1126/science.1099745

Cabeza, R., \& St Jacques, P. (2007). Functional neuroimaging of autobiographica memory. Trends in Cognitive Sciences, 11, 219-227. http://dx.doi.org/10.1016/ j.tics.2007.02.005

Cerqueira, J. J., Almeida, O. F. X. \& Sousa, N. (2008). The stressed prefrontal cortex. Left? Right!. Brain Behavior and Immunity, 22, 630-638. http://dx.doi.org/10.1016/j.bbi.2008.01.005

Cerqueira, J. J., Mailliet, F., Almeida, O. F. X., Jay, T. M., \& Sousa, N. (2007) The prefrontal cortex as a key target of the maladaptive response to stress Journal of Neuroscience, 27, 2781-2787. http://dx.doi.org/10.1523/jneurosci. 4372-06.2007

Chen, J. J., Zhou, C. J., Wu, B., Wang, Y., Li, Q., Wei, Y. D., et al. (2013). Left versus right repetitive transcranial magnetic stimulation in treating major depression: A meta-analysis of randomised controlled trials. Psychiatry Research, 210 , 1260-1264. http://dx.doi.org/10.1016/j.psychres.2013.09.007

Choi, S. W., Chi, S. E., Chung, S. Y., Kim, J. W., Ahn, C. Y., \& Kim, H. T. (2011). Is alpha wave neurofeedback effective with randomized clinical trials in depression? A pilot study. Neuropsychobiology, 63, 43-51.

Chou, C.-Y., La Marca, R., Steptoe, A., \& Brewin, C. R. (2014). Heart rate, startle response, and intrusive trauma memories. Psychophysiology, 51, 236-246. http://dx.doi.org/10.1111/psyp.12176

Clark, C. R., McFarlane, A. C., Morris, P., Weber, D. L., Sonkkilla, C., Shaw, M., et al. (2003). Cerebral function in posttraumatic stress disorder during verbal working memory updating: A positron emission tomography study. Biological Psychiatry. 53, 474-481. http://dx.doi.org/10.1016/S0006-3223(02)01505-6

Coan, J. A., \& Allen, J. J. B. (2003). The state and trait nature of frontal EEG asymmetry in emotion. In K. Hugdahl, \& R. J. Davidson (Eds.), The asymmetrical brain (pp. 565-615). Cambridge: MIT Press.

Coan, J. A., \& Allen, J. J. B. (2004). Frontal EEG asymmetry as a moderator and mediator of emotion. Biological Psychology, 67, 7-49. http://dx.doi.org/10.1016 j.biopsycho.2004.03.002 
Coan, J. A., Allen, J. J. B., \& Harmon-Jones, E. (2001). Voluntary facial expression and hemispheric asymmetry over the frontal cortex. Psychophysiology, 38, 912-925. http://dx.doi.org/10.1111/1469-8986.3860912

Coan, J. A., Allen, J. J. B., \& McKnight, P. E. (2006). A capability model of individual differences in frontal EEG asymmetry. Biological Psychology, 72, 198-207. http://dx.doi.org/10.1016/j.biopsycho.2005.10.003

Curtis, W. J., \& Cicchetti, D. (2007). Emotion and resilience: A multilevel investigation of hemispheric electroencephalogram asymmetry and emotion regulation in maltreated and nonmaltreated children. Development and Psychopathology, 19, 811-840. http://dx.doi.org/10.1017/s0954579407000405

Davidson, R.J. (1998). Affective style and affective disorders: Perspectives from affective neuroscience. Cognition E'Emotion, 12, 307-330. http://dx.doi.org/10.1080/ 026999398379628

Davidson, R. J. (2000). Affective style, psychopathology, and resilience: Brain mechanisms and plasticity. American Psychologist, 55, 1196-1214. http://dx.doi.org 10.1037/0003-066X.55.11.1196

Davidson, R. J. (2004). What does the prefrontal cortex "do" in affect: Perspectives on frontal EEG asymmetry research. Biological Psychology, 67, 219-233. http://dx.doi.org/10.1016/j.biopsycho.2004.03.008

Davis, M., Walker, D. L., \& Lee, Y. L. (1997). Roles of the amygdala and bed nucleus of the stria terminalis in fear and anxiety measured with the acoustic startle reflex-Possible relevance to PTSD. Annals of the New York Academy of Sciences, 821, 305-331. http://dx.doi.org/10.1111/j.1749-6632.1997.tb48289.x

Dolcos, F., Iordan, A. D., Kragel, J., Stokes, J., Campbell, R., McCarthy, G., et al. (2013). Neural correlates of opposing effects of emotional distraction on working memory and episodic memory: An event-related FMRI investigation. Frontiers in Psychology, 4 http://dx.doi.org/10.3389/fpsyg.2013.00293

Drabant, E. M., McRae, K., Manuck, S. B., Hariri, A. R., \& Gross, J. J. (2009) Individual differences in typical reappraisal use predict amygdala and prefrontal responses. Biological Psychiatry, 65, 367-373. http://dx.doi.org/10.1016/ j.biopsych.2008.09.007

Dyck, M., Loughead, J., Kellermann, T., Boers, F., Gur, R. C., \& Mathiak, K. (2011). Cognitive versus automatic mechanisms of mood induction differentially activate left and right amygdala. NeuroImage, 54, 2503-2513. http://dx.doi.org/10.1016/ j.neuroimage.2010.10.013

Epstein, C. M., Sekino, M., Yamaguchi, K., Kamiya, S., \& Ueno, S. (2002). Asymmetries of prefrontal cortex in human episodic memory: Effects of transcranial magnetic stimulation on learning abstract patterns. Neuroscience Letters, 320, 5-8. http://dx.doi.org/10.1016/s0304-3940(01)02573-3

Etkin, A., \& Wager, T. D. (2007). Functional neuroimaging of anxiety: A meta-analysis of emotional processing in PTSD, social anxiety disorder, and specific phobia. American Journal of Psychiatry, 164, 1476-1488. http://dx.doi.org/10.1176 appi.ajp.2007.07030504

Falconer, E., Bryant, R., Felmingham, K. L., Kemp, A. H., Gordon, E., Peduto, A., et al (2008). The neural networks of inhibitory control in posttraumatic stress disorder. Journal of Psychiatry and Neuroscience, 33, 413-422.

Fani, N., Jovanovic, T., Ely, T. D., Bradley, B., Gutman, D., Tone, E. B., et al. (2012) Neural correlates of attention bias to threat in post-traumatic stress disorder Biological Psychology, 90, 134-142.

Fletcher, P. C., \& Henson, R. N. A. (2001). Frontal lobes and human memory-Insights from functional neuroimaging. Brain, 124, 849-881. http://dx.doi.org/10.1093/ brain/124.5.849

Forbes, D., Elhai, J. D., Lockwood, E., Creamer, M., Frueh, B. C., \& Magruder, K. M. (2012). The structure of posttraumatic psychopathology in veterans attending primary care. Journal of Anxiety Disorders, 26, 95-101. http://dx.doi.org/10.1016/ j.janxdis.2011.09.004

Francati, V., Vermetten, E., \& Bremner, J. D. (2007). Functional neuroimaging studies in posttraumatic stress disorder: Review of current methods and findings. Depression and Anxiety, 24, 202-218. http://dx.doi.org/10.1002/da. 20208

Friedman, M. J., Resick, P. A., Bryant, R. A., \& Brewin, C. R. (2011). Considering PTSD for DSM-5. Depression and Anxiety, 28, 750-769.

Gilboa, A. (2004). Autobiographical and episodic memory-One and the same? Evidence from prefrontal activation in neuroimaging studies. Neuropsychologia, 42, 1336-1349. http://dx.doi.org/10.1016/j.neuropsychologia.2004.02. 014

Goldman, R. I. Stern, J. M., Engel, J. \& Cohen, M. S. (2002). Simultaneous EEG and fMRI of the alpha rhythm. Neuroreport, 13, 2487-2492. http://dx.doi.org/10.1097/ 01.wnr.0000047685.08940.d0

Gordon, E., Palmer, D. M., \& Cooper, N. (2010). EEG alpha asymmetry in schizophrenia, depression, PTSD, panic disorder, ADHD and conduct disorder. Clinical EEG and Neuroscience, 41, 178-183. http://dx.doi.org/10.1177/ 155005941004100404

Greenberg, D. L., Rice, H. J., Cooper, J. J., Cabeza, R., Rubin, D. C., \& LaBar, K. S. (2005). Co-activation of the amygdala, hippocampus and inferior frontal gyrus during autobiographical memory retrieval. Neuropsychologia, 43, 659-674. http://dx.doi.org/10.1016/j.neuropsychologia.2004.09.002

Grimm, A. Hulse, L., Preiss, M., \& Schmidt, S. (2012). Post- and peritraumatic stress in disaster survivors: An explorative study about the influence of individual and event characteristics across different types of disasters. European Journal of Psychotraumatology, 3 http://dx.doi.org/10.3402/ejpt.v3i0.7382

Grimm, S., Beck, J., Schuepbach, D., Hell, D., Boesiger, P., Bermpohl, F., et al. (2008). Imbalance between left and right dorsolateral prefrontal cortex in major depression is linked to negative emotional judgment: An fMRI study in severe major depressive disorder. Biological Psychiatry, 63, 369-376. http://dx.doi.org/ 10.1016/j.biopsych.2007.05.033
Gross, J. J., \& Thompson, R. A. (2007). Emotion regulation: Conceptual foundations. In J. J. Gross (Ed.), Handbook of emotion regulation (pp. 3-24). New York, NY: The Guilford Press,

Habib, R., Nyberg, L., \& Tulving, E. (2003). Hemispheric asymmetries of memory: The HERA model revisited. Trends in Cognitive Sciences, 7, 241-245. http://dx.doi.org/ 10.1016/s1364-6613(03)00110-4

Hagemann, D. (2004). Individual differences in anterior EEG asymmetry: Methodological problems and solutions. Biological Psychology, 67, 157-182. http://dx.doi.org/10.1016/j.biopsycho.2004.03.006

Hagemann, D., Naumann, E., \& Thayer, J. F. (2001). The quest for the EEG reference revisited: A glance from brain asymmetry research. Psychophysiology, 38 847-857. http://dx.doi.org/10.1017/S0048577201001081

Harmon-Jones, E., Gable, P. A., \& Peterson, C. K. (2010). The role of asymmetric fronta cortical activity in emotion-related phenomena: A review and update. Biological Psychology, 84, 451-462.

Hellawell, S. J., \& Brewin, C. R. (2002). A comparison of flashbacks and ordinary autobiographical memories of trauma: Cognitive resources and behavioura observations. Behaviour Research and Therapy, 40, 1143-1156. http://dx.doi.org/ 10.1016/s0005-7967(01)00080-8

Heller, W. (1993). Neuropsychological mechanisms of individual differences in emotion, personality, and arousal. Neuropsychology, 7, 476-489.

Henson, R. N. A., Rugg, M. D., Shallice, T., \& Dolan, R. J. (2000). Confidence in recognition memory for words: Dissociating right prefrontal roles in episodic retrieval. Journal of Cognitive Neuroscience, 12, 913-923.

Hewig, J., Schlotz, W., Gerhards, F., Breitenstein, C., Lürken, A., \& Naumann, E. (2008). Associations of the cortisol awakening response (CAR) with cortical activation asymmetry during the course of an exam stress period. Psychoneuroendocrinology, 33, 83-91. http://dx.doi.org/10.1016/j.psyneuen.2007.10.004

Holmes, E. A., \& Bourne, C. (2008). Inducing and modulating intrusive emotional memories: A review of the trauma film paradigm. Acta Psychologica, 127, 553-566. http://dx.doi.org/10.1016/j.actpsy.2007.11.002

Hopper, J. W., Frewen, P. A., van der Kolk, B. A., \& Lanius, R. A. (2007). Neural correlates of reexperiencing, avoidance, and dissociation in PTSD: Symptom dimensions and emotion dysregulation in responses to script-driven trauma imagery. Journal of Traumatic Stress, 20, 713-725. http://dx.doi.org/10.1002/jts.20284

Inslicht, S. S., Otte, C., McCaslin, S. E., Apfel, B. A., Henn-Haase, C., Metzler, T., et al. (2011). Cortisol awakening response prospectively predicts peritraumatic and acute stress reactions in police officers. Biological Psychiatry, 70, 1055-1062.

Jaworska, N., Berrigan, L., Ahmed, A. G., Gray, J., Bradford, J., Korovessis, A., et al. (2012). Resting electrocortical activity in adults with dysfunctional anger: A pilot study. Psychiatry Research: Neuroimaging, 203, 229-236.

Kemp, A. H., Griffiths, K., Felmingham, K. L., Shankman, S. A., Drinkenburg W., Arns, M., et al. (2010). Disorder specificity despite comorbidity: Resting EEG alpha asymmetry in major depressive disorder and post-traumatic stress disorder. Biological Psychology, 85, 350-354. http://dx.doi.org/10.1016 j.biopsycho.2010.08.001

Kessler, R. C., Sonnega, A., Bromet, E., Hughes, M., \& Nelson, C. B. (1995). Posttraumatic stress disorder in the National Comorbidity Survey. Archives of General Psychiatry, 52, 1048-1060. http://dx.doi.org/10.1001/ archpsyc.1995.03950240066012

Kilpatrick, D. G., Resnick, H. S., \& Acierno, R. (2009). Should PTSD criterion A be retained? Journal of Traumatic Stress, 22, 374-383. http://dx.doi.org/10.1002/ jts.20436

Kilpatrick, L., \& Cahill, L. (2003). Amygdala modulation of parahippocampal and frontal regions during emotionally influenced memory storage. NeuroImage, 20 2091-2099. http://dx.doi.org/10.1016/j.neuroimage.2003.08.006

King, J. A., Hartley, T., Spiers, H. J., Maguire, E. A., \& Burgess, N. (2005). Anterior prefrontal involvement in episodic retrieval reflects contextual interference. NeuroImage, 28, 256-267. http://dx.doi.org/10.1016/j.neuroimage.2005.05.057

Klimesch, W. (1999). EEG alpha and theta oscillations reflect cognitive and memory performance: A review and analysis. Brain Research Reviews, 29, 169-195. http://dx.doi.org/10.1016/s0165-0173(98)00056-3

Klimesch, W., Sauseng, P., \& Hanslmayr, S. (2007). EEG alpha oscillations: The inhibition-timing hypothesis. Brain Research Reviews, 53, 63-88. http://dx. doi.org/10.1016/j.brainresrev.2006.06.003

Koenigs, M., \& Grafman, J. (2009). Posttraumatic stress disorder: The role of medial prefrontal cortex and amygdala. Neuroscientist, 15, 540-548. http://dx.doi.org/ $10.1177 / 1073858409333072$

Kompus, K., Hugdahl, K., Öhman, A., Marklund, P., \& Nyberg, L. (2009). Distinct control networks for cognition and emotion in the prefrontal cortex. Neuroscience Letters, 467, 76-80. http://dx.doi.org/10.1016/j.neulet.2009.10.005

Koslov, K., Mendes, W. B., Pajtas, P. E., \& Pizzagalli, D. A. (2011). Asymmetry in resting intracortical activity as a buffer to social threat. Psychological Science, 22 641-649. http://dx.doi.org/10.1177/0956797611403156

Kurchakova, M. S., Tarabrina, N. V., Illarionova, M. D., \& Grishkova, O. S. (2009). Correlation of evoked potentials indices with characteristics of traumatic stress in combatant. Psikhologicheskii Zhurnal, 30, 96-106.

Kvavilashvili, L. (2014). Solving the mystery of intrusive flashbacks in posttraumatic stress disorder: Comment on Brewin (2014). Psychological Bulletin, 140, 98-104. http://dx.doi.org/10.1037/a0034677

Lang, P. J., Bradley, M. M. \& Cuthbert, B. N. (2005). International Affective Picture System (IAPS): Instruction manual and affective ratings. In Technical report A-6. Gainesville, FL: University of Florida.

Lanius, R. A., Bluhm, R. L., Coupland, N. J., Hegadoren, K. M., Rowe, B., Théberge J., et al. (2010). Default mode network connectivity as a predictor of post-traumatic stress disorder symptom severity in acutely traumatized 
subjects. Acta Psychiatrica Scandinavica, 121, 33-40. http://dx.doi.org/10.1111/ j.1600-0447.2009.01391.x

Laufs, H., Kleinschmidt, A., Beyerle, A., Eger, E., Salek-Haddadi, A., Preibisch, C., et al. (2003). EEG-correlated fMRI of human alpha activity. NeuroImage, 19, 1463-1476. http://dx.doi.org/10.1016/S1053-8119(03)00286-6

Lehrner, A., \& Yehuda, R. (2014). Biomarkers of PTSD: Military applications and considerations. European Journal of Psychotraumatology, 5 http://dx.doi.org/ 10.3402/ejpt.v5.23797

Lewis, R. S., Weekes, N. Y., \& Wang, T. H. (2007). The effect of a naturalistic stressor on frontal EEG asymmetry, stress, and health. Biological Psychology, 75, 239-247. http://dx.doi.org/10.1016/j.biopsycho.2007.03.004

Leyman, L., De Raedt, R., Vanderhasselt, M. A., \& Baeken, C. (2009). Influence of high-frequency repetitive transcranial magnetic stimulation over the dorsolateral prefrontal cortex on the inhibition of emotional information in healthy volunteers. Psychological Medicine, 39, 1019-1028. http://dx.doi.org/ 10.1017/s0033291708004431

Linden, M., Baumann, K., Rotter, M., \& Schippan, B. (2008). Posttraumatic embitterment disorder in comparison to other mental disorders. Psychotherapy and Psychosomatics, 77, 50-56. http://dx.doi.org/10.1159/000110060

Lommen, M. J. J., Engelhard, I. M., Sijbrandij, M., van den Hout, M. A., \& Hermans, D. (2013). Pre-trauma individual differences in extinction learning predict posttraumatic stress. Behaviour Research and Therapy, 51, 63-67. http://dx.doi.org/10.1016/j.brat.2012.11.004

Maier, S. F., \& Watkins, L. R. (2010). Role of the medial prefrontal cortex in coping and resilience. Brain Research, 1355, 52-60. http://dx.doi.org/10.1016/ j.brainres.2010.08.039

Manenti, R., Cotelli, M., Calabria, M., Maioli, C., \& Miniussi, C. (2010). Ther role of the dorsolateral prefrontal cortex in retrieval from long-term memory depends on strategies: A repetitive transcranial magnetic stimulation study. Neuroscience, 166, 501-507. http://dx.doi.org/10.1016/j.neuroscience.2009.12.037

McCaffrey, R. J., Lorig, T. S., Pendrey, D. L., McCutcheon, N. B., \& Garrett, J. C. (1993). Odor-induced EEG changes in PTSD Vietnam veterans. Journal of Traumatic Stress, 6, 213-224

McHugh, T., Forbes, D., Bates, G., Hopwood, M., \& Creamer, M. (2012). Anger in PTSD: Is there a need for a concept of PTSD-related posttraumatic anger? Clinical Psychology Review, 32, 93-104. http://dx.doi.org/10.1016/j.cpr.2011.07.013

McMenamin, B., \& Marsolek, C. (2013). Can theories of visual representation help to explain asymmetries in amygdala function? Cognitive, Affective, E Behavioral Neuroscience, 13, 211-224. http://dx.doi.org/10.3758/s13415-012-0139-1

McNally, R. J. (2006). Cognitive abnormalities in post-traumatic stress disorder. Trends in Cognitive Sciences, 10, 271-277. http://dx.doi.org/10.1016/ j.tics.2006.04.007

McNally, R. J., \& Robinaugh, D. J. (2011). Risk factors and posttraumatic stress disorder: Are they especially predictive following exposure to less severe stressors? Depression and Anxiety, 28, 1091-1096. http://dx.doi.org/10.1002/da.20867

Metzger, L. J., Paige, S. R., Carson, M. A., Lasko, N. B., Paulus, L. A., Pitman, R. K., et al. (2004). PTSD arousal and depression symptoms associated with increased rightsided parietal EEG asymmetry. Journal of Abnormal Psychology, 113, 324-329. http://dx.doi.org/10.1037/0021-843x.113.2.324

Meyer, T., Otgaar, H., \& Smeets, T. (2015). Flashbacks, intrusions, mindwandering-Instances of an involuntary memory spectrum: A commentary on Takarangi, Strange, and Lindsay (2014). Consciousness and Cognition, 33, 24-29. http://dx.doi.org/10.1016/j.concog.2014.11.012

Meyer, T., Quaedflieg, C. W. E. M., Giesbrecht, T., Meijer, E., Abiad, S., \& Smeets, T. (2014). Frontal EEG asymmetry as predictor of physiological responses to aversive memories. Psychophysiology, 51, 853-865.

Meyer, T., Smeets, T., Giesbrecht, T., Quaedflieg, C. E. M., Girardelli, M., Mackay, G. N., et al. (2013). Individual differences in spatial configuration learning predict the occurrence of intrusive memories. Cognitive, Affective, E'Behavioral Neuroscience, 13, 186-196. http://dx.doi.org/10.3758/s13415-012-0123-9

Miller, G. A., Crocker, L. D., Spielberg, J. M., Infantolino, Z. P., \& Heller, W. (2013). Issues in localization of brain function: The case of lateralized frontal cortex in cognition, emotion, and psychopathology. Frontiers in Integrative Neuroscience, 7 http://dx.doi.org/10.3389/fnint.2013.00002

Moores, K. A., Clark, C. R., McFarlane, A. C., Brown, G. C., Puce, A., \& Taylor, D. J. (2008). Abnormal recruitment of working memory updating networks during maintenance of trauma-neutral information in post-traumatic stress disorder. Psychiatry Research: Neuroimaging, 163, 156-170.

O’Doherty, D. C., Chitty, K. M., Saddiqui, S., Bennett, M. R., \& Lagopoulos, J. in press. A systematic review and meta-analysis of magnetic resonance imaging measurement of structural volumes in posttraumatic stress disorder. Psychiatry Research: Neuroimaging. doi: 10.1016/j.pscychresns.2015.01.002.

Ochsner, K. N., Bunge, S. A., Gross, J. J., \& Gabrieli, J. D. E. (2002). Rethinking feelings: An fMRI study of the cognitive regulation of emotion. Journal of Cognitive Neuroscience, 14, 1215-1229. http://dx.doi.org/10.1162/089892902760807212

Ochsner, K. N., \& Gross, J. J. (2005). The cognitive control of emotion. Trends in Cognitive Sciences, 9, 242-249. http://dx.doi.org/10.1016/j.tics.2005.03.010

Orr, S. P., \& Roth, W. T. (2000). Psychophysiological assessment: Clinical applications for PTSD. Journal of Affective Disorders, 61, 225-240. http://dx.doi.org/ 10.1016/S0165-0327(00)00340-2

Osuch, E. A., Benson, B. E., Luckenbaugh, D. A., Geraci, M., Post, R. M., \& McCann, U. (2009). Repetitive TMS combined with exposure therapy for PTSD: A preliminary study. Journal of Anxiety Disorders, 23, 54-59. http://dx.doi.org/10.1016/j.janxdis.2008.03.015

Pallanti, S., \& Bernardi, S. (2009). Neurobiology of repeated transcranial magnetic stimulation in the treatment of anxiety: A critical review.
International Clinical Psychopharmacology, 24, 163-173. http://dx.doi.org/ 10.1097/YIC.0b013e32832c2639

Parvaz, M., MacNamara, A., Goldstein, R., \& Hajcak, G. (2012). Event-related induced frontal alpha as a marker of lateral prefrontal cortex activation during cognitive reappraisal. Cognitive, Affective, E' Behavioral Neuroscience, 12, 730-740. http://dx.doi.org/10.3758/s13415-012-0107-9

Patel, R., Spreng, R. N., Shin, L. M., \& Girard, T. A. (2012). Neurocircuitry models of posttraumatic stress disorder and beyond: a meta-analysis of functional neuroimaging studies. Neuroscience E' Biobehavioral Reviews, 36, 2130-2142. http://dx.doi.org/10.1016/j.neubiorev.2012.06.003

Peeters, F., Ronner, J., Bodar, L., van Os, J., \& Lousberg, R. (2014). Validation of a neurofeedback paradigm: Manipulating frontal EEG alpha-activity and its impact on mood. International Journal of Psychophysiology, 93, 116-120. http://dx.doi.org/10.1016/j.ijpsycho.2013.06.010

Peres, J. F. P., Foerster, B., Santana, L. G., Fereira, M. D., Nasello, A. G., Savoia M., et al. (2011). Police officers under attack: Resilience implications of an fMRI study. Journal of Psychiatric Research, 45, 727-734. http://dx.doi.org/ 10.1016/j.jpsychires.2010.11.004

Pfurtscheller, G., Stancak, A., \& Neuper, C. (1996). Event-related synchronization (ERS) in the alpha band-An electrophysiological correlate of cortical idling: A review. International Journal of Psychophysiology, 24, 39-46. http://dx.doi.org/10.1016/s0167-8760(96)00066-9

Pizzagalli, D. A., Sherwood, R. J., Henriques, J. B., \& Davidson, R. J. (2005). Frontal brain asymmetry and reward responsiveness-A source-localization study. Psychological Science, 16, 805-813.

Pole, N. (2007). The psychophysiology of posttraumatic stress disorder: A metaanalysis. Psychological Bulletin, 133, 725.

Pole, N., Neylan, T. C., Otte, C., Henn-Hasse, C., Metzler, T. J., \& Marmar, C. R. (2009). Prospective prediction of posttraumatic stress disorder symptoms using fear potentiated auditory startle responses. Biological Psychiatry, 65, 235-240. http://dx.doi.org/10.1016/j.biopsych.2008.07.015

Quaedflieg, C. W. E. M., Meyer, T., Smulders, F., \& Smeets, T. (2015). The functiona role of individual-alpha based frontal asymmetry in stress responding. Biological Psychology, 104, 75-81. http://dx.doi.org/10.1016/j.biopsycho.2014.11. 014

Rabe, S., Beauducel, A., Zöllner, T., Maercker, A., \& Karl, A. (2006). Regiona brain electrical activity in posttraumatic stress disorder after motor vehicle accident. Journal of Abnormal Psychology, 115, 687-698. http://dx.doi.org/ 10.1037/0021-843x.115.4.687

Rabe, S., Zöllner, T., Beauducel, A., Maercker, A., \& Karl, A. (2008). Changes in brain electrical activity after cognitive behavioral therapy for posttraumatic stress disorder in patients injured in motor vehicle accidents. Psychosomatic Medicine, 70, 13-19. http://dx.doi.org/10.1097/PSY.0b013e31815aa325

Rabe, S., Zöllner, T., Maercker, A., \& Karl, A. (2006). Neural correlates of posttraumatic growth after severe motor vehicle accidents. Journal of Consulting and Clinical Psychology, 74, 880-886. http://dx.doi.org/10.1037/0022-006x.74.5.880

Reid, S. A., Duke, L. M., \& Allen, J. J. B. (1998). Resting frontal electroencephalographic asymmetry in depression: Inconsistencies suggest the need to identify mediating factors. Psychophysiology, 35, 389-404.

Rosen, G. M., \& Lilienfeld, S. O. (2008). Posttraumatic stress disorder: An empirical evaluation of core assumptions. Clinical Psychology Review, 28, 837-868. http://dx.doi.org/10.1016/j.cpr.2007.12.002

Rossi, S., Innocenti, I., Polizzotto, N. R., Feurra, M., DeCapua, A., Ulivelli, M., et al (2011). Temporal dynamics of memory trace formation in the human prefronta cortex. Cerebral cortex, 21, 368-373.

Sandrini, M., Cappa, S. F., Rossi, S., Rossini, P. M., \& Miniussi, C. (2003). The role of prefrontal cortex in verbal episodic memory: rTMS evidence. Journal of Cognitive Neuroscience, 15, 855-861. http://dx.doi.org/10.1162/089892903322370771

Sandrini, M., Censor, N., Mishoe, J., \& Cohen, Leonardo G. (2013). Causal role of prefrontal cortex in strengthening of episodic memories through reconsolidation. Current Biology, 23, 2181-2184. http://dx.doi.org/10.1016/j.cub.2013.08.045

Schmidt, U., Kaltwasser, S. F., \& Wotjak, C. T. (2013). Biomarkers in posttraumatic stress disorder: Overview and implications for future research. Disease Markers, 35, 43-54. http://dx.doi.org/10.1155/2013/835876

Schutter, D. J. L. G., \& Harmon-Jones, E. (2013). The corpus callosum: A commissural road to anger and aggression. Neuroscience E' Biobehavioral Reviews, 37. 2481-2488. http://dx.doi.org/10.1016/j.neubiorev.2013.07.013

Segrave, R. A., Cooper, N. R., Thomson, R. H., Croft, R. J., Sheppard, D. M., \& Fitzgerald, P. B. (2011). Individualized alpha activity and frontal asymmetry in major depression. Clinical EEG and Neuroscience, 42, 45-52.

Shankman, S. A., Silverstein, S. M., Williams, L. M., Hopkinson, P. J., Kemp, A H., Felmingham, K. L., et al. (2008). Resting electroencephalogram asymmetry and posttraumatic stress disorder. Journal of Traumatic Stress, 21, 190-198. http://dx.doi.org/10.1002/jts.20319

Shin, L. M., Rauch, S. L., \& Pitman, R. K. (2006). Amygdala, medial prefrontal cortex and hippocampal function in PTSD. In R. Yehuda (Ed.), Psychobiology of posttraumatic stress disorder: A decade of progress (Vol. 1071) (pp. 67-79). Boston, MA: New York Academy of Science.

Spielberg, J. M., Miller, G. A., Engels, A. S., Herrington, J. D., Sutton, B. P., Banich, M. T., et al. (2011). Trait approach and avoidance motivation: Lateralized neural activity associated with executive function. NeuroImage, 54, 661-670. http://dx.doi.org/10.1016/j.neuroimage.2010.08.037

Spielberg, J. M., Miller, G. A., Warren, S. L., Engels, A. S., Crocker, L. D., Sutton, B. P., et al. (2012). Trait motivation moderates neural activation associated with goal pursuit. Cognitive Affective E Behavioral Neuroscience, 12, 308-322. http://dx.doi.org/10.3758/s13415-012-0088-8 
St Jacques, P. L., Botzung, A., Miles, A., \& Rubin, D. C. (2011). Functional neuroimaging of emotionally intense autobiographical memories in posttraumatic stress disorder. Journal of Psychiatric Research, 45, 630-637. http://dx.doi.org/10.1016/j.jpsychires.2010.10.011

Stewart, J. L., Coan, J. A., Towers, D. N., \& Allen, J. J. B. (2011). Frontal EEG asymmetry during emotional challenge differentiates individuals with and without lifetime major depressive disorder. Journal of Affective Disorders, 129, 167-174. http://dx.doi.org/10.1016/j.jad.2010.08.029

Sullivan, R. M., \& Gratton, A. (2002). Prefrontal cortical regulation of hypothalamic-pituitary-adrenal function in the rat and implications for psychopathology: Side matters. Psychoneuroendocrinology, 27, 99-114. http://dx. doi.org/10.1016/s0306-4530(01)00038-5

Suvak, M. K., \& Barrett, L. F. (2011). Considering PTSD from the perspective of brain processes: A psychological construction approach. Journal of Traumatic Stress, 24, 3-24. http://dx.doi.org/10.1002/jts.20618

Svoboda, E., McKinnon, M. C., \& Levine, B. (2006). The functional neuroanatomy of autobiographical memory: A meta-analysis. Neuropsychologia, 44, 2189-2208. http://dx.doi.org/10.1016/j.neuropsychologia.2006.05.023

Tenke, C. E., \& Kayser, J. (2005). Reference-free quantification of EEG spectra: Combining current source density (CSD) and frequency principal components analysis (fPCA). Clinical Neurophysiology, 116, 2826-2846. http://dx.doi.org/10.1016/j.clinph.2005.08.007

Thayer, J. F., Ahs, F., Fredrikson, M., Sollers, J. J., \& Wager, T. D. (2012). A meta-analysis of heart rate variability and neuroimaging studies: Implications for heart rate variability as a marker of stress and health. Neuroscience and Biobehavioral Reviews, 36, 747-756. http://dx.doi.org/10.1016/j.neubiorev.2011.11.009

Thibodeau, R., Jorgensen, R. S., \& Kim, S. (2006). Depression, anxiety, and resting frontal EEG asymmetry: A meta-analytic review. Journal of Abnormal Psychology, 115, 715-729. http://dx.doi.org/10.1037/0021-843x.115.4.715

Tillman, G. D., Kimbrell, T. A., Calley, C. S., Kraut, M. A., Freeman, T. W., \& Hart, J. (2011). Repetitive transcranial magnetic stimulation and threat memory: Selective reduction of combat threat memory $\mathrm{P} 300$ response after right frontal-lobe stimulation. Journal of Neuropsychiatry and Clinical Neurosciences, 23, 40-47. http://dx.doi.org/10.1176/appi.neuropsych.23.1.40

Turriziani, P., Smirni, D., Zappala, G., Mangano, G. R., Oliveri, M., \& Cipolotti, L. (2012). Enhancing memory performance with rTMS in healthy subjects and individuals with Mild Cognitive Impairment: the role of the right dorsolateral prefrontal cortex. Frontiers in Human Neuroscience, 6 http://dx.doi.org/10.3389/fnhum.2012.00062

Van Praag, H. M., Asnis, G. M., Kahn, R. S., Brown, S. L., Korn, M., Friedman, J. M. H., et al. (1990). Nosological tunnel vision in biological psychiatry: A plea for a functional psychopathology. Annals of the New York Academy of Sciences, 600, 501-510. http://dx.doi.org/10.1111/j.1749-6632.1990.tb16905.x

van Wingen, G. A., Geuze, E., Vermetten, E., \& Fernandez, G. (2011). Perceived threat predicts the neural sequelae of combat stress. Molecular Psychiatry, 16, 664-671.

van Zuiden, M., Geuze, E., Willemen, H. L. D. M., Vermetten, E., Maas, M., Amarouchi, K., et al. (2012). Glucocorticoid receptor pathway components predict posttraumatic stress disorder symptom development: A prospective study. Biological Psychiatry, 71, 309-316. http://dx.doi.org/10.1016/j.biopsych.2011.10.026

Velo, J. R., Stewart, J. L., Hasler, B. P., Towers, D. N., \& Allen, J. J. B. (2012). Should it matter when we record? Time of year and time of day as factors influencing frontal EEG asymmetry. Biological Psychology, 91, 283-291.

Vogt, B. A., Finch, D. M., \& Olson, C. R. (1992). Functional heterogeneity in cingulate cortex: The anterior executive and posterior evaluative regions. Cerebral cortex, 2, 435-443.

Wager, T. D., Phan, K. L., Liberzon, I., \& Taylor, S. F. (2003). Valence, gender, and lateralization of functional brain anatomy in emotion: A meta-analysis of findings from neuroimaging. NeuroImage, 19, 513-531. http://dx.doi.org/10.1016/ s1053-8199(03)00078-8

Wahbeh, H., \& Oken, B. S. (2013). Peak high-frequency HRV and peak alpha frequency higher in PTSD. Applied Psychophysiology and Biofeedback, 38, 57-69. http://dx.doi.org/10.1007/s10484-012-9208-z

Weigand, A., Grimm, S., Astalosch, A., Guo, J. S., Briesemeister, B. B., Lisanby, S. H., et al. (2013). Lateralized effects of prefrontal repetitive transcranial magnetic stimulation on emotional working memory. Experimental Brain Research, 227. 43-52. http://dx.doi.org/10.1007/s00221-013-3483-7

Wiedemann, G., Pauli, P., Dengler, W., Lutzenberger, W., Birbaumer, N., \& Buchkremer, G. (1999). Frontal brain asymmetry as a biological substrate of emotions in patients with panic disorders. Archives of General Psychiatry, 56, 78-84.

Zoellner, L. A., Bedard-Gilligan, M. A., Jun, J. J., Marks, L. H., \& Garcia, N. M. (2013), The evolving construct of posttraumatic stress disorder (PTSD): DSM-5 criteria changes and legal implications. Psychological Injury and Law, 6, 277-289. http://dx.doi.org/10.1007/s12207-013-9175-6

Zoellner, L. A., Pruitt, L. D., Farach, F. J., \& Jun, J. J. (2014). Understanding heterogeneity in PTSD: Fear, dysphoria, and distress. Depression and Anxiety, 31, 97-106. http://dx.doi.org/10.1002/da.22133

Zoladz, P. R., \& Diamond, D. M. (2013). Current status on behavioral and biological markers of PTSD: A search for clarity in a conflicting literature. Neuroscience \& Biobehavioral Reviews, 37, 860-895. http://dx.doi.org/10.1016/ j.neubiorev.2013.03.024 